\title{
Article
}

Subscriber access provided by King Abdullah University of Science and Technology Library

\section{Degradation of carbonyl hydroperoxides in the atmosphere and in combustion}

Lili Xing, Junwei Lucas Bao, Zhandong Wang, Feng Zhang, and Donald G. Truhlar

J. Am. Chem. Soc., Just Accepted Manuscript • DOI: 10.1021/jacs.7b08297 • Publication Date (Web): 12 Oct 2017

Downloaded from http://pubs.acs.org on October 18, 2017

\section{Just Accepted}

"Just Accepted" manuscripts have been peer-reviewed and accepted for publication. They are posted online prior to technical editing, formatting for publication and author proofing. The American Chemical Society provides "Just Accepted" as a free service to the research community to expedite the dissemination of scientific material as soon as possible after acceptance. "Just Accepted" manuscripts appear in full in PDF format accompanied by an HTML abstract. "Just Accepted" manuscripts have been fully peer reviewed, but should not be considered the official version of record. They are accessible to all readers and citable by the Digital Object Identifier (DOI®). "Just Accepted" is an optional service offered to authors. Therefore, the "Just Accepted" Web site may not include all articles that will be published in the journal. After a manuscript is technically edited and formatted, it will be removed from the "Just Accepted" Web site and published as an ASAP article. Note that technical editing may introduce minor changes to the manuscript text and/or graphics which could affect content, and all legal disclaimers and ethical guidelines that apply to the journal pertain. ACS cannot be held responsible for errors or consequences arising from the use of information contained in these "Just Accepted" manuscripts. 


\title{
Degradation of carbonyl hydroperoxides in the atmosphere and in combustion
}

\author{
Lili Xing, ${ }^{1,2}$ Junwei Lucas Bao,, ${ }^{2, *}$ Zhandong Wang, ${ }^{3}$ Feng Zhang,, ${ }^{1, *}$ and Donald G.Truhlar ${ }^{2,{ }^{*}}$ \\ ${ }^{1}$ National Synchrotron Radiation Laboratory, University of Science and Technology of China, Hefei, Anhui 230029, \\ China \\ ${ }^{2}$ Department of Chemistry, Chemical Theory Center, and Minnesota Supercomputing Institute, University of Min- \\ nesota, Minnesota 55455-0431, USA \\ ${ }^{3}$ Clean Combustion Research Center, King Abdullah University of Science and Technology, Thuwal, 23955-69oo, \\ Saudi Arabia
}

\begin{abstract}
Oxygenates with carbonyl and hydroperoxy functional groups are important intermediates that are generated during the autooxidation of organic compounds in the atmosphere and during the autoignition of transport fuels. In the troposphere, the degradation of carbonyl hydroperoxides leads to low-vapor-pressure polyfunctional species that may precipitate in clouds and fog droplets or to the formation of secondary organic aerosols (SOAs). In combustion, the fate of carbonyl hydroperoxides is important for the performance of advanced combustion engines, especially for autoignition. A key fate of the carbonyl hydroperoxides is reaction with $\mathrm{OH}$ radicals, for which kinetics data are experimentally unavailable. Here, we study 4-hydroperoxy-2-pentanone $\left(\mathrm{CH}_{3} \mathrm{C}(=\mathrm{O}) \mathrm{CH}_{2} \mathrm{CH}(\mathrm{OOH}) \mathrm{CH}_{3}\right)$ as a model compound to clarify the kinetics of $\mathrm{OH}$ reactions with carbonyl hydroperoxides, in particular $\mathrm{H}$-atom abstraction and $\mathrm{OH}$ addition reactions. With a combination of electronic structure calculations, we determine previously missing thermochemical data, and with multipath variational transition state theory (MP-VTST), a multidimensional tunneling (MT) approximation, multiplestructure anharmonicity, and torsional potential anharmonicity we obtained much more accurate rate constants than the ones that can computed by conventional single-structure harmonic transition state theory (TST) and than the empirically estimated rate constants that are currently used in atmospheric and combustion modeling. The roles of various factors in determining the rates are elucidated. The pressure-dependent rate constants for the addition reaction are computed using system-specific quantum RRK theory. The calculated temperature range is $298-2400 \mathrm{~K}$, and the pressure range is o.o1$100 \mathrm{~atm}$. The accurate thermodynamic and kinetics data determined in this work are indispensable in the global modeling of SOAs in atmospheric science and in the detailed understanding and prediction of ignition properties of hydrocarbons and alternative fuels.
\end{abstract}

\section{INTRODUCTION}

Biologically generated and anthropogenic organic compounds are precursors for tropospheric ozone and secondary organic aerosols (SOAs). ${ }^{1}$ The atmospheric autooxidation of organic compounds is usually initiated from reactions with oxidants, e.g., $\mathrm{OH}, \mathrm{NO}_{3}$, and $\mathrm{O}_{3}$, to produce radical intermediates, which then react with $\mathrm{O}_{2}$ and form peroxy radicals $\left(\mathrm{RO}_{2}\right)$. The fates of peroxy radicals play important roles in the degradation of organic compounds, which undergo intramolecular $\mathrm{H}$-atom migration or bimolecular reactions with $\mathrm{HO}_{2}, \mathrm{NO}, \mathrm{RO}_{2}$, etc. ${ }^{2,3}$

Oxygenates with carbonyl and hydroperoxy functionalities constitute an important class of intermediates in organic autooxidation. Recent studies have shown that the ozonolysis of unsaturated organic compounds (e.g., longchain alkenes and monoterpenes) leads to highly oxidized molecules with multiple carbonyl and hydroperoxy functional groups, and these are a major source of SOAs. ${ }^{4,5}$
Scheme 1a-c shows the potential reaction pathways to carbonyl hydroperoxides from the atmospheric autooxidation of alcohols, ketones, and peroxides. The reactions of carbonyl hydroperoxides with $\mathrm{OH}$ radicals are expected to be important degradation routes in the troposphere. ${ }^{2,5}$ The resulting carbonyl hydroperoxy radicals may react with $\mathrm{O}_{2}$ and lead to large $\mathrm{RO}_{2}$ radicals. The further reactions of the large $\mathrm{RO}_{2}$ radicals lead to low-vapor-pressure intermediates, which may precipitate in cloud and fog droplets or in the formation of SOAs. The reaction with $\mathrm{OH}$ is also important in combustion, where $\mathrm{OH}$ radicals are known to be important in all stages of ignition. ${ }^{6}$

The chemistry of peroxy radicals also controls the autooxidation of organic compounds in combustion (e.g., at 500-700 K). ${ }^{7}$ The intramolecular $\mathrm{H}$-atom migration of peroxy radical, followed by $\mathrm{O}_{2}$ addition, intramolecular $\mathrm{H}-$ atom migration, and decomposition produces carbonyl hydroperoxides. ${ }^{8-10}$ Scheme 1 shows the pathway to a car- 
bonyl hydroperoxide from the autooxidation of $n$-pentane and other compounds. The produced carbonyl hydroperoxide serves as a major chain-branching agent in hydrocarbon autoignition. ${ }^{711-15}$ On one hand, carbonyl hydroperoxides $\left(\mathrm{HOOQ}^{\prime}=\mathrm{O}\right)$ allow low-temperature chain branching because they have hydroperoxy groups with weak $\mathrm{O}-\mathrm{O}$ bonds that decompose easily to $\mathrm{OH}$ and alkoxy radicals. On the other hand, the $\mathrm{H}$-atom abstraction reactions on carbonyl hydroperoxides may play a significant role, thus decreasing the chain branching effect of the competing initiation reactions. Therefore we must know the fate of carbonyl hydroperoxides to engage in accurate ignition modeling. However, the $\mathrm{H}$-abstraction from carbonyl hydroperoxides is seldom considered in kinetics modeling, ${ }^{16}$ and the reaction pathways and kinetics are not well known. ${ }^{17-19}$ Furthermore, it is almost impossible to measure the rates of these $\mathrm{H}$-abstraction reactions because carbonyl hydroperoxide species are very reactive; therefore theoretical calculations can fill a gap in the knowledge that is essential for understanding carbonyl hydroperoxide chemistry.
(a)
(b)
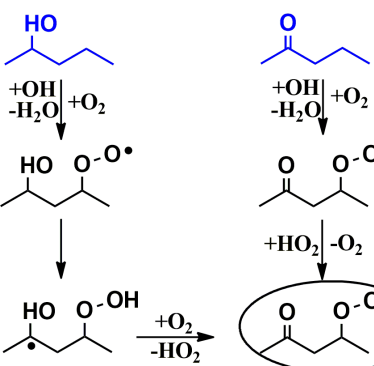
$+{ }_{-\mathrm{H}_{2} \mathrm{O}}^{+\mathrm{OH}}++\mathrm{O}^{-}$<smiles>CC(=O)CC(C)O[O]</smiles>

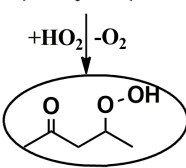

Scheme 1. Reaction scheme for the production of carbonyl hydroperoxide from the autooxidation of (a) 2pentanol, (b) 2-pentanone, (c) 2-pentylperoxide, and (d) $n$-pentane.

In this work, we select a pentyl carbonyl hydroperoxide (4-hydroperoxy-2-pentanone) as a model compound to investigate the kinetics of the reaction of $\mathrm{OH}$ with a carbonyl hydroperoxide; 4-hydroperoxy-2-pentanone is a keto hydroperoxides, and it will be called KHP for convenience hereafter. The reaction mechanism including both $\mathrm{H}$-atom abstraction and $\mathrm{OH}$ radical addition is presented in Scheme 2. As described in previous studies by Sharma et al. $^{20}$ and Goldsmith et al., ${ }^{21}$ hindered internal rotation in hydroperoxy and alkylperoxy radicals cannot be described accurately by independent $1 \mathrm{D}$ rotors due to variations in the torsional barriers that arise from the presence or absence of hydrogen bonding interactions. These fascinating features prompt us to explore the kinetics of H-abstraction of carbonyl hydroperoxide to elucidate the species responsible for chain branching reactions, as well as for SOA formation.

In this work, we compute the potential energy surfaces for hydrogen abstraction from different sites of KHP by $\mathrm{OH}$ radical and then use multi-path variational transition state theory ${ }^{22,23}$ (MP-VTST) with multi-dimensional tunneling contributions ${ }^{24}$ to compute the rate constants for producing each of the possible products. These rate calcu-

lations include multiple-structure anharmonicity and torsional potential anharmonicity. We also consider the addition reaction, for which we use system-specific quantum Rice-Ramsperger-Kassel (SS-QRRK) theory with the Lindemann-Hinshelwood thermal activation mechanism ${ }^{25-27}$ to compute the thermal rate constants as functions of pressure.

\section{METHODS}

2.1 Electronic structure methods. As the first step, an exhaustive conformational search was carried out by optimizing all the initial conformers that are generated through rotating all the torsional bonds (except for methyl group) using the MSTor program. ${ }^{28-30}$ The preliminary conformational structure search and geometry optimization were performed using the Mo8-HX exchange correlation functional ${ }^{31}$ with the $\mathrm{MG}_{3} \mathrm{~S}$ basis set. The $\mathrm{MG}_{3} \mathrm{~S}$ basis set $^{32}$ is identical to the $6-311+G(2 d f, 2 p)$ basis set ${ }^{33,34}$ for $H$, $\mathrm{C}$, and $\mathrm{O}$ atoms.

(a)

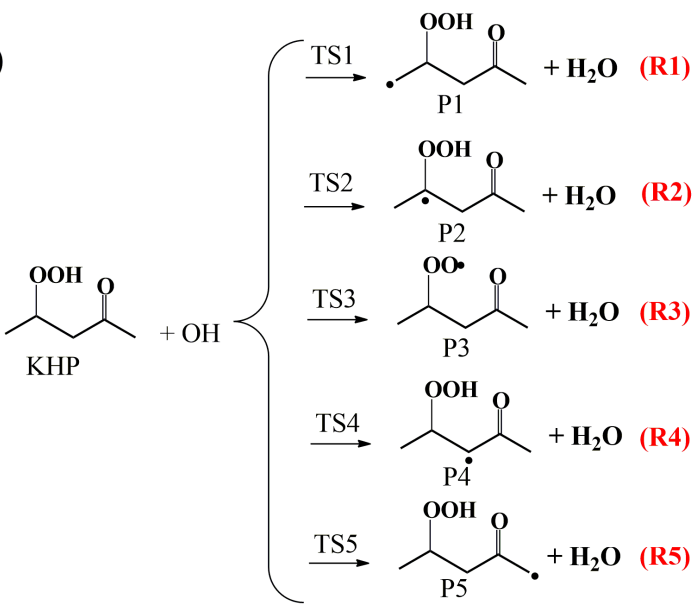

(b)

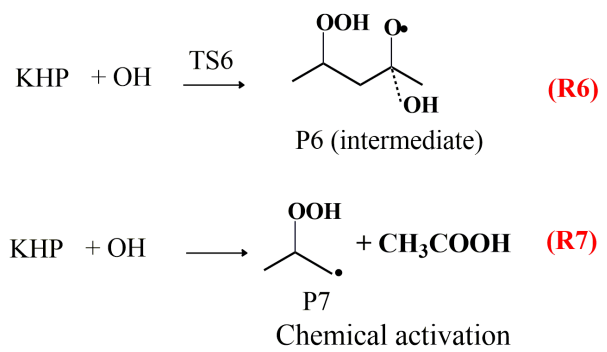

Scheme 2. Reactions of $\mathrm{OH}$ with 4-hydroperoxy-2pentanone. (R1-R5): hydrogen abstraction; (R6): the formation of the stabilized intermediate adduct; $\left(R_{7}\right)$ : hydroxide addition followed by decomposition of an intermediate to form bimolecular products. Products are labeled with the prefix P; and transition states are labeled with the prefix TS.

Single-point energy calculations were performed at Mo8-HX/MG3S geometries using eleven density functionals $^{31,35-44}$ ) with the $\mathrm{MG}_{3} \mathrm{~S}$ and jul-cc-pVTZ ${ }^{45}$ basis sets. To test and validate the density functionals for the present dynamics calculations, we performed benchmark calculations by the explicitly correlated electronic structure 
method $\operatorname{CCSD}(\mathrm{T})-\mathrm{F}_{12} \mathrm{a}^{46,47}$ with the jun-cc-pVTZ basis set. ${ }^{8}$ The CCSD(T)-F12a/jun-cc-pVTZ calculations can be viewed as an efficient way to approximate the complete basis set (CBS) limit of the $\operatorname{CCSD}(\mathrm{T})$ method. ${ }^{49}$

The distinguishable conformers that were found by the preliminary conformer search with the Mo8-HX/MG3S method were re-optimized by the electronic structure method selected on the basis of having the smallest MUE in the tests of the previous paragraph. Frequency analyses were also performed by that method.

Both the SCF calculations and the geometry optimizations were performed with tight convergence criteria. The density functional integrations were carried out by a grid of 99 radial shells per atom with 974 angular points per shell. All the electronic structure calculations were performed using Gaussian og software ${ }^{50}$ with the locally developed MN-GFM6.7 module..$^{51}$ The $\operatorname{CCSD(T)-F12a}$ calculations were carried out by using the Molpro program. ${ }^{52}$

2.2 Thermodynamics and Kinetics. The multistructural method with coupled torsional-potential anharmonicity $^{53}$ (MS-T) was used for calculating enthalpies, entropies, and heat capacities as functions of temperature. The MS-T partition functions were calculated using the MSTor code. $^{28-30}$ All structures have a rotational symmetry number of 1 .

We carried out first-principles direct dynamics calculations using multistructural canonical variational transition state theory with small curvature tunneling (MS$\mathrm{CVT} / \mathrm{SCT})^{54}$ to calculate the high-pressure-limit rate constants of reactions R1-R6. For the hydrogen abstraction reactions $\mathrm{R}_{1}-\mathrm{R}_{5}$ we also performed calculations by more complete multipath canonical variational transition state theory with small curvature tunneling (MP-CVT/SCT). ${ }^{22-}$ 24,53,55,56 And for the current system which contains one chiral carbon, we follow the procedures in the previous paper $^{56}$ for treating chiral centers in MS- and MP-VTST theory. The dynamics calculations were performed using the Polyrate 2016-2 $A^{57}$ and Gaussrate 2017 codes. ${ }^{58}$

The minimum energy paths (MEPs) needed for the calculations were calculated in isoinertial coordinates using the Page-McIver method, which is called the local quadratic approximation (LQA) in the original reference, ${ }^{59}$ and using the reorientation of the dividing surface (RODS) algorithm. ${ }^{60}$ The step size was $0.0026 \AA$, and the Hessians were updated every 10 steps along the reaction path. Vibrational frequencies were scaled by 0.975 , as determined in a standard way, ${ }^{61}$ to account for vibrational anharmonicity and systematic errors in the electronic structure.

Vibrational frequencies along the reaction path were calculated using nonredundant internal coordinates ${ }^{62,63}$ for R2-R6. For R1, redundant internal coordinates ${ }^{64}$ were used because it has a doubly degenerate linear bend. ${ }^{65}$

The multidimensional tunneling contributions (MT) for each path were evaluated with the small-curvature tunneling approximation (SCT). ${ }^{24,66}$ The vibrationally adiabatic ground-state energy, which is the effective potential for tunneling, is given by:

$$
V_{\mathrm{a}}^{\mathrm{G}}=V_{\mathrm{MEP}}(s)+\varepsilon^{\mathrm{G}}(s)
$$

where $s$ is the reaction coordinate, which is a signed distance from the saddle point along each curved MEP in isoinertial coordinates, $V_{\mathrm{MEP}}(s)$ is the potential energy along the MEP, and $\varepsilon^{G}(s)$ is the local zero point energy.

The MS-VTST rate constants are calculated by ${ }^{54}$

$$
k^{\mathrm{MS}-\mathrm{CVT} / \mathrm{SCT}}=F_{\mathrm{act}}^{\mathrm{MS}-\mathrm{T}} k_{1}^{\mathrm{SS}-\mathrm{CVT} / \mathrm{SCT}}
$$

where $k_{1}^{\mathrm{SS}-\mathrm{CVT} / \mathrm{SCT}}$ is the single-structural canonical variation theory ${ }^{67}$ (CVT) rate constant with the multidimensional small curvature tunneling (SCT) approximation, ${ }^{24}$ which employs the lowest-energy structure (labeled as 1 here) for reactants and the transition state. $F_{\mathrm{act}}^{\mathrm{MS}-\mathrm{T}}$ is the multi-structural torsional anharmonicity factor of the reaction - it includes the contributions from all the conformational structures of the reactants and the transition state and is computed by the coupled-potential MS-T method as described elsewhere. ${ }^{25-27,55}$ It is computed by

$$
F_{\mathrm{act}}^{\mathrm{MS}-\mathrm{T}}=F_{\mathrm{TS}}^{\mathrm{MS}-\mathrm{T}} / F_{\mathrm{R}}^{\mathrm{MS}-\mathrm{T}}
$$

where $F_{\mathrm{X}}^{\mathrm{MS}-\mathrm{T}}$ is the multistructural torsional anharmonicity factor of species $\mathrm{X}$, and it equals the ratio of the MS-T partition function to the single-structure harmonic one. As in the original MS-VTST method, $F_{\mathrm{TS}}^{\mathrm{MS}-\mathrm{T}}$ was approximated by its value at the conventional transition state. In the MS-T method, the potential for the torsional coordinate $\phi_{j, \tau}$ of torsion $\tau$ of structure $j$ of a given species is approximated locally as

$$
V_{j, \tau}=U_{j}+A_{j, \tau}\left[1-\cos M_{j, \tau}\left(\phi_{j, \tau}-\phi_{j, \tau, \mathrm{eq}}\right)\right]
$$
where $U_{j}$ is the energy of the structure, $\phi_{j, \tau}$, eq is the equilibrium value of the torsion angle, $M_{j, \tau}$ is the local periodicity, determined by Voronoi tessellation, and $A_{j, \tau}$ is determined from the second-order force constants and the local periodicities. ${ }^{53}$ Effects caused by the deviation of eq $2 \mathrm{c}$ from a harmonic potential are called torsional potential anharmonicity effects; the effect of including the contributions of all the distinguishable structures of a species (a reactant species or a transition state) is called multiplestructure anharmonicity. The combination of these two effects is called multistructural anharmonicity.

MP-VTST is an extension of multi-structural variational transition state theory, and the MP-VTST rate constants are

$$
k^{\mathrm{MP}-\mathrm{CVT} / \mathrm{SCT}}=F_{\mathrm{act}}^{\mathrm{MS}-\mathrm{T}}\langle\gamma\rangle_{P} k_{1}^{\mathrm{ConTST}}
$$

Here $k_{1}^{\text {ConTST }}$ is the conventional transition state theory rate constant calculated by using the global minimum reactant and global-minimum transition structure without tunneling (calculations with quantized vibrational levels but without tunneling are called quasiclassical); and $\langle\gamma\rangle_{P}$ is the path-averaged generalized transmission coefficient ${ }^{68}$ which includes, for each reaction path, both the variational effect and the multidimensional tunneling (MT) contributions:

$$
\langle\gamma\rangle_{P}=\frac{\sum_{p=1}^{P} \kappa_{p}^{\mathrm{MT}} \Gamma_{p}^{\mathrm{CVT}} Q_{p}^{\mathrm{SS}-\mathrm{T}}}{\sum_{p=1}^{P} Q_{p}^{\ddagger-\mathrm{SS}-\mathrm{T}}}
$$

where $P$ is the number of reaction paths involved in the MP-VTST calculations, and $Q_{p}^{\ddagger-S S-T}$ is the single-structural rovibrational partition function of the transition state computed with torsional anharmonicity for path $p ; \Gamma_{P}^{\mathrm{CVT}}$ is the recrossing transmission coefficient for path $p$; and $\kappa_{P}^{\mathrm{MT}}$ is the multidimensional tunneling transmission coefficient for path $p$. 
Note that the recrossing transmission coefficient could also be called the quasiclassical transmission coefficient; it is also sometimes called the variational effect because it accounts for the difference between variational transition state theory and conventional transion state theory when both are applied without tunneling. Its deviation from unity is a measure of the extent to which VTST accounts for the breakdown of the no-recrossing assumption of quasiclassical transition state theory at the conventional transition state that passes through the saddle point. (For example, a recrossing transmission coefficient of 0.7 means that $30 \%$ of the quasiclassical flux through the conventional transition state does not contribute to the net one-way flux because the true dynamical bottleneck is the variational transition state, not the conventional transition state.)

Reactions R6 and R7 (see Scheme 2) have pressuredependent rate constants because there is a unimolecular intermediate (P6) in the reaction mechanism. These reactions can be described by the following chemical activation mechanism: ${ }^{25}$

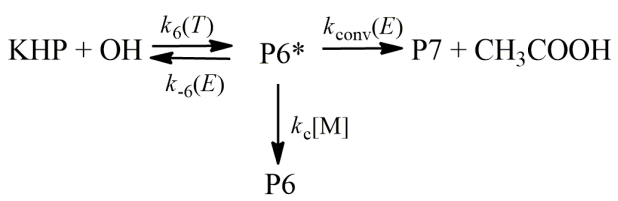

where $T$ is temperature, $\mathrm{M}$ is the bath gas, $\mathrm{P}^{*}$ is the energized adduct, P6 is the (stabilized) addition product, $k_{\mathrm{c}}$ is the collisional deactivation rate constant, and $k_{\text {conv }}(E)$ is the energy-dependent unimolecular dissociation rate constant of the energized species $\mathrm{P}^{*}$, i.e., the rate constant for conversion of the energized intermediate to product.

The formation of the stabilized adduct P6 is called reaction R6 and the rate constant for producing stabilized P6 is denoted as $k_{\mathrm{R} 6}$ and is defined as $(d[\mathrm{P} 6] / d t) /([\mathrm{OH}][\mathrm{KHP}])$. The unimolecular dissociation of $\mathrm{P}^{*}$ to produce $\mathrm{P}_{7}$ and $\mathrm{CH}_{3} \mathrm{COOH}$ is defined as reaction $\mathrm{R}_{7}$; and the rate constant for the formation of $\mathrm{P}_{7}$ and $\mathrm{CH}_{3} \mathrm{COOH}$ is defined as $\left.k_{\mathrm{R}_{7}}=\mathrm{d}\left[\mathrm{P}_{7}\right] / \mathrm{dt}\right) /([\mathrm{OH}][\mathrm{KHP}]$. The pressure-dependent rate constants $k_{\mathrm{R} 6}$ and $k_{\mathrm{R}_{7}}$ were computed using system-specific quantum RRK theory ${ }^{25,26}$ (SSQRRK) combined with the chemical activation mechanism. The critical energy and frequency factor of the SSQRRK treatment are set equal to the high-pressure-limit temperature-dependent Arrhenius parameters (see SI for the activation energy for each reaction) computed from the fitting formula (see eqs 4 and 5 in section 3.5) for the rate constants. The L-J potential parameters needed for $k_{\mathrm{c}}$ were chosen as follows: $\sigma_{1}=5.71 \AA$, $\varepsilon_{1} / k_{B}=510.67 \mathrm{~K}$ for P6; and for the bath gas $\mathrm{Ar}, \sigma_{2}=3.47 \AA$ and $\varepsilon_{2} / k_{B}=114.0 \mathrm{~K}$ respectively. The average energy transferred per deactivating collision, which plays an important role in the falloff effect, $^{69}$ is taken to be $\langle\Delta E\rangle_{\text {down }}=\Theta(\mathrm{T} / 300)^{0.85}$ with $\Theta=$ $300 \mathrm{~cm}^{-1}$; this simple power law representation for $\langle\Delta E\rangle_{\text {down }}$ has proven to allow for a reasonable reproduction of experimental data across a wide range of temperature and pressure. ${ }^{70-72}$ In previous work, Jalan et al. ${ }^{73}$ adopted a value of $150 \mathrm{~cm}^{-1}$ for $\Theta$ for the ketohydroperoxide of pro- pane; based on this and the empirical rule that "larger species generally having larger values", ${ }^{70-72}$ the value of $\Theta$ is taken as $300 \mathrm{~cm}^{-1}$ in the present paper (and we will also report sensitivity checks). The formulas relating $k_{\mathrm{c}}$ to $\langle\Delta E\rangle_{\text {down }}$ are given elsewhere. ${ }^{26,74}$

\section{RESULTS AND DISCUSSION}

3.1 Electronic structure calculations. In this work, we tested eleven density functionals. Comparing with the relatively accurate $\mathrm{CCSD}(\mathrm{T})-\mathrm{F}_{12 a}$ /jun-cc-pVTZ method, the Mo8-HX/jul-cc-pVTZ method was selected as an affordable electronic structure method because it has the smallest mean unsigned error (MUE), in particular 0.51 $\mathrm{kcal} / \mathrm{mol}$ for the forward and reverse barrier heights and energies of reaction ( 21 data points). Full details of these tests are given in the Supporting Information (SI). Table 1 shows the calculated forward barrier heights using our selected method and the benchmark.

Table 1. Calculated forward barrier heights (kcal/mol) for R1-R6.

\begin{tabular}{lllllll}
\hline \multicolumn{7}{c}{ Forward barrier height } \\
& $\mathrm{R}_{1}$ & $\mathrm{R} 2$ & $\mathrm{R}_{3}$ & $\mathrm{R} 4$ & $\mathrm{R}$ & $\mathrm{R} 6$ \\
\hline Mo8-HX & -0.08 & -4.76 & -2.73 & 1.06 & 1.15 & 0.7 \\
& & & & & & 9 \\
$\operatorname{CCSD}(\mathrm{T})$ & 0.99 & -4.38 & -2.61 & 0.8 & 1.44 & 2.6 \\
& & & & 8 & & 0 \\
\hline
\end{tabular}

3.2 Multistructural torsional anharmonicity. All of the torsional bonds except the methyl group were rotated by 0,120 , and -120 degrees to generate various initial conformational structures. The torsional potential anharmonicity of all the torsions, including the methyl groups (which do not generate additional distinguishable structures) are included in the partition functions; and in this work, the MS-T partition functions are computed at a full $^{75}$ high-level (i.e., by Mo8-HX/jul-cc-pVTZ). For KHP and TS1-TS6, the numbers of torsions (excluding the $\mathrm{CH}_{3}$ group) and distinguishable structures for KHP and TS1TS6 are 4/38, 7/179, 6/50,6/90, 6/59, 7/136 and 5/74 respectively.

The numbers of distinguishable structures in each of nine energy ranges for each of the species are shown in Figure 1. For KHP, the energy difference between the lowest and highest of the 38 structures is relatively small, being equal to $6.2 \mathrm{kcal} / \mathrm{mol}$. However for TS1, the energy difference between the lowest and highest of the 179 structures is relative largely, being $9.9 \mathrm{kcal} / \mathrm{mol}$. 


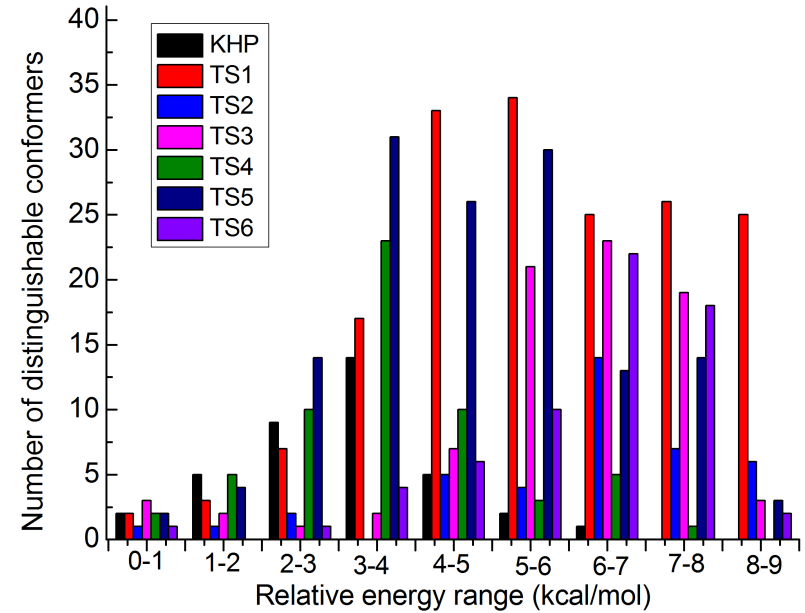

Figure 1. Number of distinguishable conformers in each relative potential energy range for reactant (KHP), and transition states (TS1-TS6). For KHP, the energy of the global-minimal structure is chosen as the zero of the relative energy, and for the transition states the energies are relative to the lowestenergy transition state for that reaction.

Table 2 illustrates the effect of multiple-structure anharmonicity and torsional potential anharmonicity on the partition functions of KHP by comparing the conformational-rotational-vibrational partition function of KHP calculated by using the multistructural approximation with torsional anharmonicity (MS-T) and the multistructural local harmonic (MS-LH) approximation to the rotational-vibrational partition function of the lowestenergy structure (which is the single-structure harmonic (SS-HO) approximation. The MS-LH approximation, which neglects torsional potential anharmonicity but includes multiple-structure anharmonicity, overestimates the best estimate by $4-22 \%$ at $298-1000 \mathrm{~K}$, but by much greater amounts (up to a factor of 2.3) at higher temperatures. The MS-T approximation exceeds the SS-HO result by a factor increasing from 13 at $298 \mathrm{~K}$ to 162 at $2400 \mathrm{~K}$. Therefore, the standard approach found in textbooks that ignores multiple structures introduces large errors in partition functions.

All the local periodicities of structures of the reactant and of transition states $\mathrm{TS}_{2}$ and $\mathrm{TS}_{3}$ are given for illustration in Figure 2. (The local periodicities of TS 1 and TS4TS6 are provided in the SI.) The physical meaning of the $M_{\mathrm{j}, \tau}$ parameter was explained in detail in the original MS$\mathrm{T}$ paper ${ }^{76}$. but a rough explanation is that it tells us the average effective numbers of minima along the torsional coordinates. Figure 2 shows that the local periodicities are usually between 2 and 3 . The most significant reason why we see a variety of $M_{\mathrm{j}, \mathrm{\tau}}$ values in Figure 2 is the influence of hydrogen bonding in some of the structures.
Table 2. Conformational-rotational-vibrational partition functions of KHP with the multi-structural torsional method (MS-T) and multistructural local harmonic (MS-LH) approximation including all structures and the single-structure harmonic rotationalvibrational partition function (SS-HO) of the lowestenergy structure of KHP. ${ }^{a}$

\begin{tabular}{cccc}
\hline$T(\mathrm{~K})$ & $Q_{\text {con-rovib }}^{\text {MS-T }}$ & $Q_{\text {con-rovib }}^{\text {MS-LH }}$ & $Q_{\text {rovib }, 1}^{\text {SS-HO }}$ \\
\hline 298 & $5.84 \mathrm{E}-59$ & $7.15 \mathrm{E}-59$ & $4.64 \mathrm{E}-60$ \\
400 & $3.43 \mathrm{E}-4 \mathrm{O}$ & $3.81 \mathrm{E}-4 \mathrm{O}$ & $1.27 \mathrm{E}-41$ \\
600 & $9.36 \mathrm{E}-21$ & $9.76 \mathrm{E}-21$ & $1.41 \mathrm{E}-22$ \\
800 & $4.98 \mathrm{E}-10$ & $5.33 \mathrm{E}-10$ & $4.68 \mathrm{E}-12$ \\
1000 & $6.81 \mathrm{E}-03$ & $7.78 \mathrm{E}-03$ & $4.93 \mathrm{E}-05$ \\
1500 & $1.12 \mathrm{E}+09$ & $1.61 \mathrm{E}+09$ & $6.36 \mathrm{E}+06$ \\
2400 & $2.38 \mathrm{E}+20$ & $5.44 \mathrm{E}+20$ & $1.47 \mathrm{E}+18$ \\
\hline
\end{tabular}

${ }^{a}$ The zero of energy for the partition functions is the energy of the lowest-energy classical equilibrium structure.

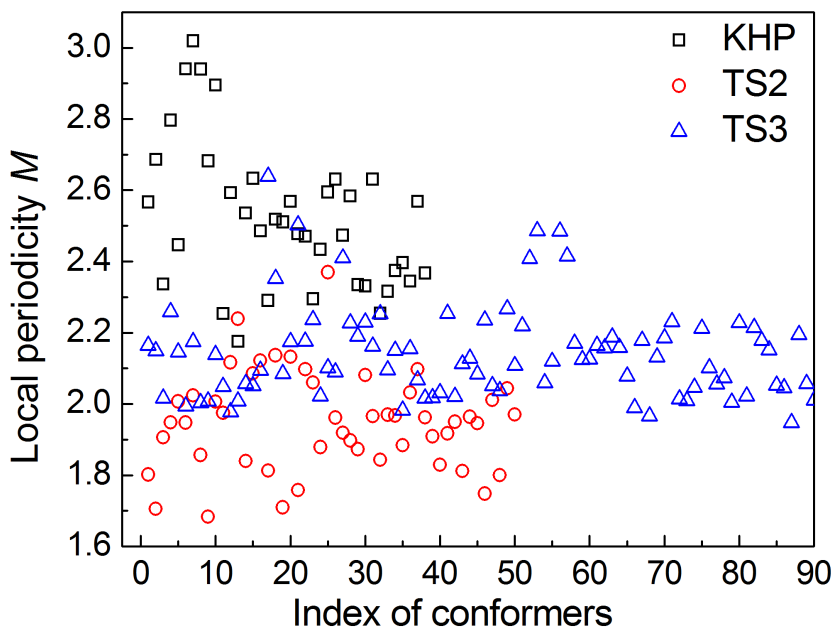

Figure 2. The unitless local periodicities $M_{j, \tau}$ for KHP, $\mathrm{TS}_{2}$, and $\mathrm{TS}_{3}$.

A hydrogen bond lowers the barrier by stabilizing the transition state. However the entropic effect of hydrogen bonding can increase the free energy of activation..$^{56} \mathrm{We}$ analyzed the hydrogen bonding by adopting the criteria defined by Chen et al. ${ }^{77}$ by which a normal hydrogen bond has the $\mathrm{H}$...O distance less than $2.4 \AA$ and the $\mathrm{O}-\mathrm{H} . . . \mathrm{O}$ angle greater than $150^{\circ}$, whereas we identify a "strongly bent hydrogen bond" as one with an $\mathrm{H}$... O distance less than $2.4 \AA$ and the $\mathrm{O}-\mathrm{H}$...O angle in the range $90^{-}-150^{\circ}$. Figure 3 (a) shows some TS structures for reactions $\mathrm{R}_{2}$ and $\mathrm{R}_{3}$; the first $P$ paths for each reaction are ordered by increasing values of their classical barrier heights and are denoted as path 1, path 2, and so on. There are two strongly bent hydrogen bonds for most of the TS2 conformers. Also $\mathrm{TS}_{3}$ (path 1) has a strongly bent hydrogen bond, and $\mathrm{TS}_{3}$ (path 2) has a normal hydrogen bond.

Figure 3 (b) shows the relative enthalpies and free energies of transition structures for $R_{3}$, both with and without a hydrogen bond. The figure shows that a non-hydrogen- 
bonded transition structure, e.g. conformer 10, although it has a higher enthalpy of activation, does not necessarily have a higher free energy of activation than conformers with hydrogen bonds (conformers 1-8) at $800 \mathrm{~K}$ and 2000 $\mathrm{K}$. This is due to the hydrogen bond reducing the entropy. Therefore a non-hydrogen-bonded structure can contribute more to the rate constant than some hydrogenbonded conformer. This phenomenon was also found in a previous study. ${ }^{56}$

(a)

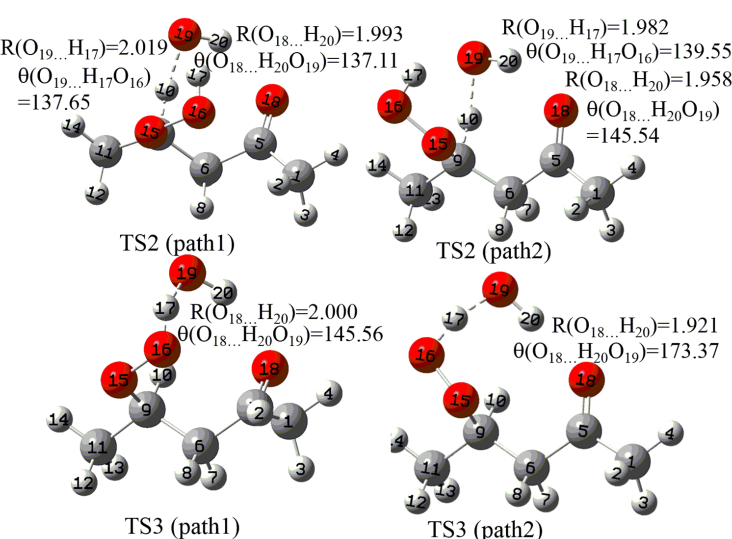

(b)

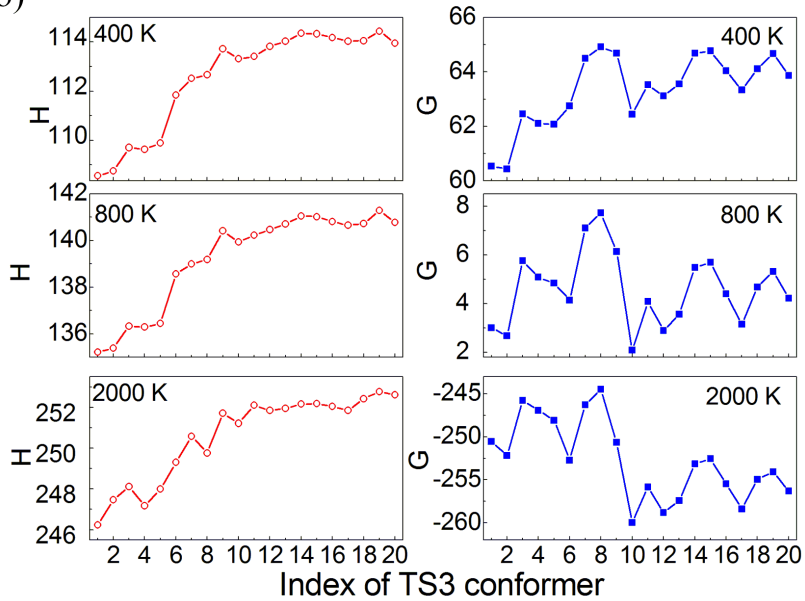

Figure 3. (a) Hydrogen bonding analysis for TS2 (path 1 and path 2) and TS 3 (path 1 and path 2), where $\mathrm{TS}_{2}$ and $\mathrm{TS}_{3}$ are the transition state structures of $\mathrm{R}_{2}$ and $\mathrm{R}_{3}$ respectively.-(b) Relative enthalpy of activation $(H)$ and relative Gibbs free energy of activation $(G)$ (both in $\mathrm{kcal} / \mathrm{mol}$ ) for $\mathrm{TS}_{3}$ (paths 1 to 20). The conformers are arranged in order of increasing classical barrier height. Paths 1-8 have hydrogen bonds; paths 920 do not have hydrogen bonds. In this figure, the thermodynamic quantities are anharmonic results for the individual structures, as calculated by MS-T, and the zero of energy is set equal to the potential energy of the energetically lowest conformer of the transition state structure that corresponds to path 1 .

Classical barrier heights $\left(V^{\ddagger}\right)$ and quantum mechanical quasithermodynamic quantities for these examples of hydrogen-bonded transition states are in Table 3. The energy barriers relative to $\mathrm{KHP}+\mathrm{OH}$ are negative, showing some stabilization; however, this does not necessarily indicate fast reaction because the entropy effect should also be taken into account. The path with the highest barrier, namely $\mathrm{TS}_{3}$ (path 2), has a larger entropy than others, this reduces the free energy of activation. In fact, it has the most favorable free energy of the four cases shown, even though it has the least favorable barrier. This shows that the effects of hydrogen bonding are subtle.

Table 3. Classical barrier heights (kcal/mol) and standard-state entropies ( $\mathrm{cal} / \mathrm{K} / \mathrm{mol})$, and free energies $(\mathrm{kcal} / \mathrm{mol})$ of selected conventional transition states (saddle points). ${ }^{a}$

\begin{tabular}{|c|c|c|c|c|}
\hline$T(\mathrm{~K})$ & $S^{\circ}$ & $G^{\circ}$ & $S^{\circ}$ & $G^{\circ}$ \\
\hline & \multicolumn{2}{|c|}{ TS2(path 1) } & \multicolumn{2}{|c|}{ TS2(path 2) } \\
\hline & \multicolumn{2}{|c|}{$V^{\ddagger}=-4.8$} & \multicolumn{2}{|c|}{$V^{\ddagger}=-3.5$} \\
\hline 298 & 104.0 & 68.6 & 106.1 & 69.3 \\
\hline 400 & 118.0 & $57 \cdot 3$ & 120.1 & $57 \cdot 7$ \\
\hline 600 & 142.4 & 31.2 & 144.5 & 31.2 \\
\hline 800 & 163.3 & 0.6 & 165.4 & 0.1 \\
\hline 1000 & 181.5 & -34.0 & 183.6 & -34.8 \\
\hline 1500 & 218.2 & -134.3 & 220.3 & -136.2 \\
\hline \multirow[t]{3}{*}{2400} & 265.4 & -353.3 & 267.5 & -357.1 \\
\hline & \multicolumn{2}{|c|}{$\mathrm{TS}_{3}$ (path 1) } & \multicolumn{2}{|c|}{ TS3(path 2) } \\
\hline & \multicolumn{2}{|c|}{$V^{\ddagger}=-2.7$} & \multicolumn{2}{|c|}{$V^{\ddagger}=-2.4$} \\
\hline 298 & 105.9 & $69 \cdot 3$ & 106.9 & 69.3 \\
\hline 400 & 120.0 & 57.8 & 120.8 & $57 \cdot 7$ \\
\hline 600 & 144.4 & 31.3 & 145.0 & 31.1 \\
\hline 800 & 165.3 & 0.3 & 165.9 & -0.1 \\
\hline 1000 & 183.3 & -34.6 & 184.1 & -35.1 \\
\hline 1500 & 220.0 & -135.9 & 221.2 & -136.9 \\
\hline 2400 & 267.1 & -356.5 & 268.6 & -358.7 \\
\hline
\end{tabular}

${ }^{a}$ The zero of energy is $\mathrm{KHP}+\mathrm{OH}$. The standard state pressure is a 1 bar ideal gas.

Figure 4 shows the multistructural torsional anharmonicity factor $F_{\mathrm{X}}^{\mathrm{MS}-\mathrm{T}}$ for each species and $F_{\mathrm{act}}^{\mathrm{MS}-\mathrm{T}}$ for each reaction at 298-2400 K. It shows that $F_{\mathrm{X}}^{\mathrm{MS}-\mathrm{T}}$ is in the range 12$161,8-2077,3-219,5-562,16-296,9-951$, and 3-1782 for $X=$ KHP and TS1-6, respectively. The multistructural torsional anharmonicity is especially large for TS1 and TS6 for $T$ > $600 \mathrm{~K}$. The multistructural anharmonicity factors for the reactions are smaller than the corresponding transition state factors due to cancellation with $F_{\mathrm{X}}^{\mathrm{MS}-\mathrm{T}}$ of the reactant KHP. The multistructural torsional anharmonicity factors $F_{\mathrm{act}}^{\mathrm{MS}-\mathrm{T}}$ are spread over the ranges o.6-13, o.2-1.4, $0.4-3.5,1.3-1.8$, 0.7-5.9, and 0.2-11 for R1-R6, respectively. Because these ranges are quite different for the different reactions, multistructural anharmonicity has a large effect on the branching ratios. 


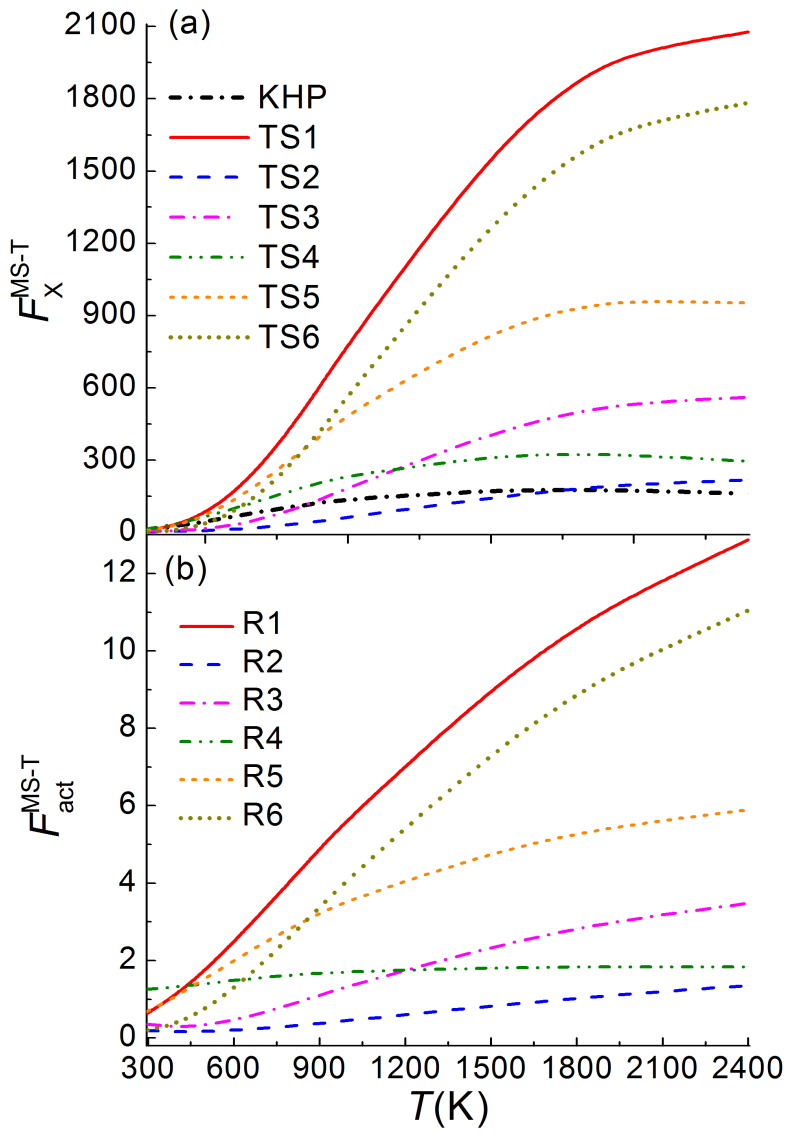

Figure 4. Multistructural torsional anharmonicity factor (a) for species, KHP and TS1-TS6; (b) for every forward reactions (R1-R6).

Because we have seen that multistructural anharmonicity plays a significant role in the partition functions, we know that it affects the accuracy of the thermodynamic quantities, such as standard-state entropy, heat capacity, relative enthalpy, and relative Gibbs free energy. Table 4 lists these quantities for KHP at 298-1000 K; results at higher temperatures are in the SI. The entropy and heat capacity obtained by the popular group additivity (GA) method $^{78,79}$ are given for comparison. The heat capacities calculated with the MS-T method considering both multistructural and torsional anharmonicity deviate by $\sim 3 \mathrm{cal}$ $\mathrm{mol}^{-1} \mathrm{~K}^{-1}$ from those obtained by the GA method at most temperatures. The MS-LH method overestimates the heat capacities especially at high temperatures $(\geq 700 \mathrm{~K})$. In the temperature range of $298-600 \mathrm{~K}$, the entropies calculated with MS-T and MS-LH are almost identical and are in reasonable agreement with those obtained by the GA method. As the temperature increases, the entropies estimated by the widely used GA method show large deviations $\left(3 \sim 10 \mathrm{cal}^{-1} \mathrm{~mol}^{-1} \mathrm{~K}\right)$ from our calculated values by the MS-T method. The SS-HO approximation has poor accuracy at all temperatures, e.g., at $298 \mathrm{~K}$, it differs by up to 9 $\mathrm{cal}^{-1} \mathrm{~mol}^{-1} \mathrm{~K}$ from the MS-T result. Due to the increasing contribution of multistructural anharmonicity with increasing temperature, the entropies calculated with MS-T and MS-LH have dramatically large deviations from those calculated by the SS-HO method and from the empirical GA results.

3.3 Variational effects. For each reaction, we included the four lowest-energy reaction paths in the MP-VTST calculations (i.e., $P=4$ ). As mentioned above, the first four paths are ordered by increasing values of their classical barrier heights and are denoted as path 1, path $2, \ldots$. The potential energy along the minimum energy path $\left(V_{\mathrm{MEP}}\right)$ and the vibrationally adiabatic ground-state potential energy $\left(V_{a}^{\mathrm{G}}\right)$ for R2 (paths 1- 4 ) are displayed in Figure 5. Note that a vibrationally adiabatic potential-energy curve is the same as a free energy of activation profile for $T=\mathrm{o} \mathrm{K}$; for all four paths of reaction $\mathrm{R}_{2}$, the location of the canonical variational transition state is near - $0.185 \AA$ at o K. At finite temperatures, the free energy of activation profiles differ from the $V_{\mathrm{a}}^{\mathrm{G}}$ curve, and the location of variational transition state is determined by the maximum of the free energy of activation profile. For instance, for path 1, at $298 \mathrm{~K}, 600 \mathrm{~K}, 1000 \mathrm{~K}, 1500 \mathrm{~K}$ and $2400 \mathrm{~K}$, the variational transition state is at -0.18o, -0.182, - - o.189, 0.201, and -0.224 $\AA$, respectively, and the vibrationally adiabatic potential energy at these locations are all in the range 93.03-93.06 kcal $/ \mathrm{mol}$. For path 2, the location of the variational transition state at these temperatures is -0.179 , -0.195, -0.221, -0.254, and -0.310 $\AA$, and the corresponding vibrationally adiabatic ground-state energies are correspondingly $94.28,94.28,94.25,94.19$, and $94.06 \mathrm{kcal} / \mathrm{mol}$. For path 1 to path 4 , as the classical barrier height increases, $V_{\mathrm{MEP}}$ and $V_{\mathrm{a}}^{\mathrm{G}}$ barriers become thinner, which is reflected in the tunneling transmission coefficients discussed in section 3.4 .

Figure 6 shows the CVT recrossing transmission coefficients for the four lowest-energy paths of R2. The results for the different paths agree with each other within a factor of 1.6, and the variational effect is significant, especially at low temperatures, e.g., the conventional TST rate constant is a factor of 8 larger than the CVT one at $T=$ $300 \mathrm{~K}$ for $\mathrm{R} 2$.

The recrossing transmission coefficients of reactions R1-R6 are shown in Figure 7. For $\mathrm{R}_{2}, \mathrm{R}_{3}, \mathrm{R}_{4}$, and $\mathrm{R}_{5}$, the recrossing transmission coefficients are between o.1 to o.6 over the whole temperature range. What causes these large variational effects? To answer this we analyzed the vibrational frequencies along the reaction path. The results for $\mathrm{R}_{2}$ are shown in Figure 8 , and the vibrational frequencies for some other reactions are provided in the SI. We find that the variational effect is mainly due to the one vibrational mode that changes dramatically along the reaction path. This mode $\left(v_{11}\right.$, shown as a dashed curve in Figure 8 ) is the $\mathrm{H}-\mathrm{C}$ stretch of the breaking bond in the reactant region, then it decreases by $\sim 1000 \mathrm{~cm}^{-1}$ from reactants to the saddle point, where is a quasisymmetric $\mathrm{C}-\mathrm{H}$ $\mathrm{O}$ stretching mode, and finally it increases as it transforms into the vibration of the new $\mathrm{H}-\mathrm{O}$ bond in the product. The reason for the decrease in the middle region is that the mode has less hydrogenic motion in that region where the hydrogenic motion is mainly in the reaction coordinate, which is an asymmetric $\mathrm{C}-\mathrm{H}-\mathrm{O}$ stretching motion there. The decrease in the middle region of 
the reaction path significantly increases the vibrational partition function of the generalized transition state when it is calculated relative to the local potential energy minimum. While the vibrational frequency is changing rapidly, the potential energy change from $s=0$ to $s=-0.106 \AA$ is less than $1.1 \mathrm{kcal} / \mathrm{mol}$, which can be seen from the relatively flat potential energy surface around the saddle point in Figure 5, so the vibrational partition function relative to $V_{\mathrm{MEP}}$ changes more than the Boltzmann factor

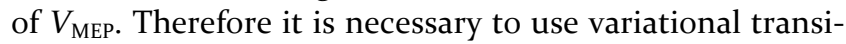
tion state theory (rather than conventional transition state theory) for treating such a reaction. This kind of large variational effect due to the mode that transforms from the bond-breaking vibration to the bond-forming vibration has been observed for many reactions in previous studies. ${ }^{64,65,67,68,80-86}$

We have discussed the effect of the key high-frequency modes, which are most important at low $T$. As the temperature increases, the lower frequencies can be very important. The lower frequencies are shown in the SI.

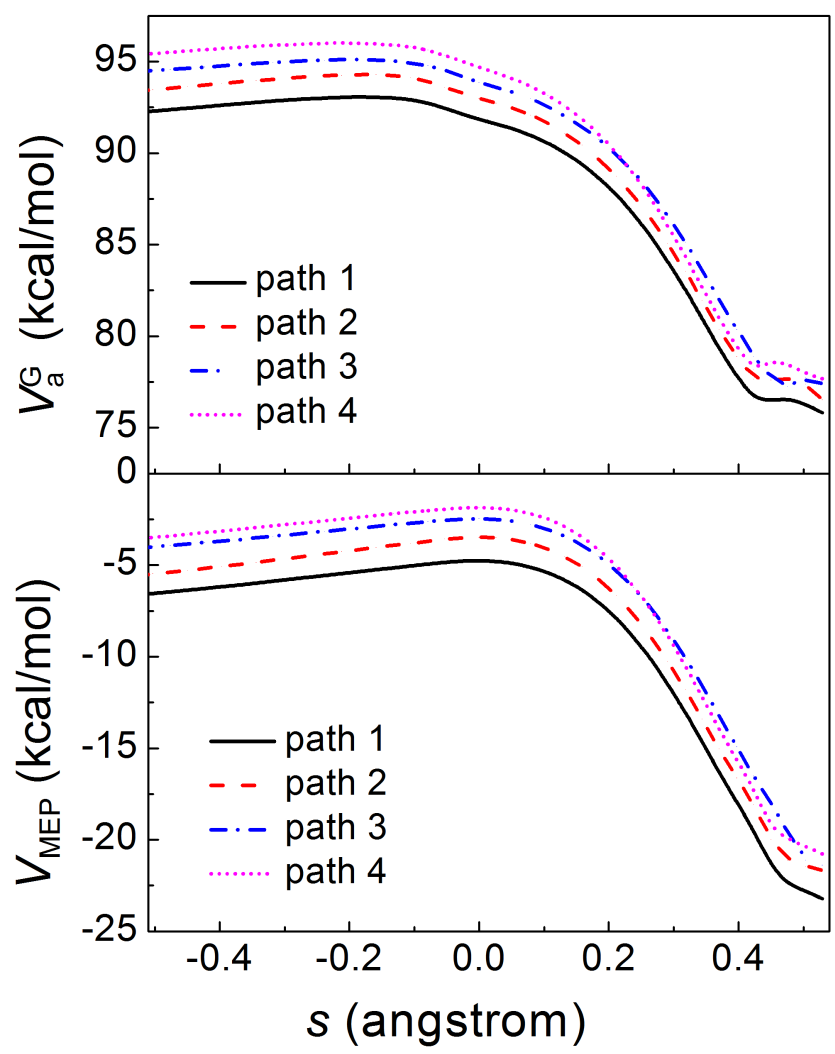

Figure 5. Vibrationally adiabatic ground-state potential energy curve $\left(V_{\mathrm{a}}^{\mathrm{G}}\right)$ and the potential energy $\left(V_{\mathrm{MEP}}\right)$ along the minimum energy path for paths $1,2,3$, and 4 of R2. Here $s$ is the signed distance from the saddle point along each curved MEP in isoinertial coordinates scaled to a reduced mass of 1 amu.

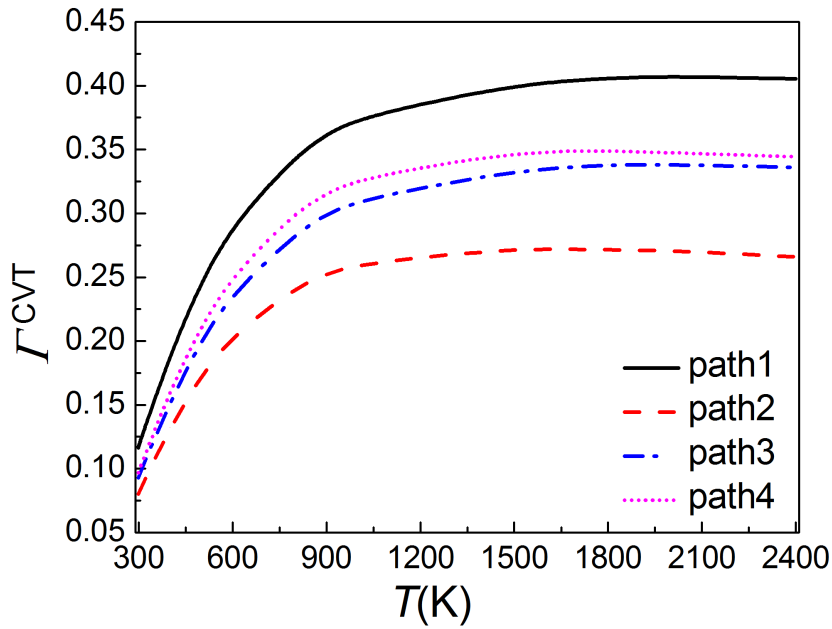

Figure 6. Canonical recrossing transmission coefficients $(\Gamma$ ${ }^{\mathrm{CVT}}$ ) for R2 at various temperatures. $\Gamma^{\mathrm{CVT}}$ are defined as the ratios of rate constants computed by quasiclassical variational TST to those computed by quasiclassical conventional TST.

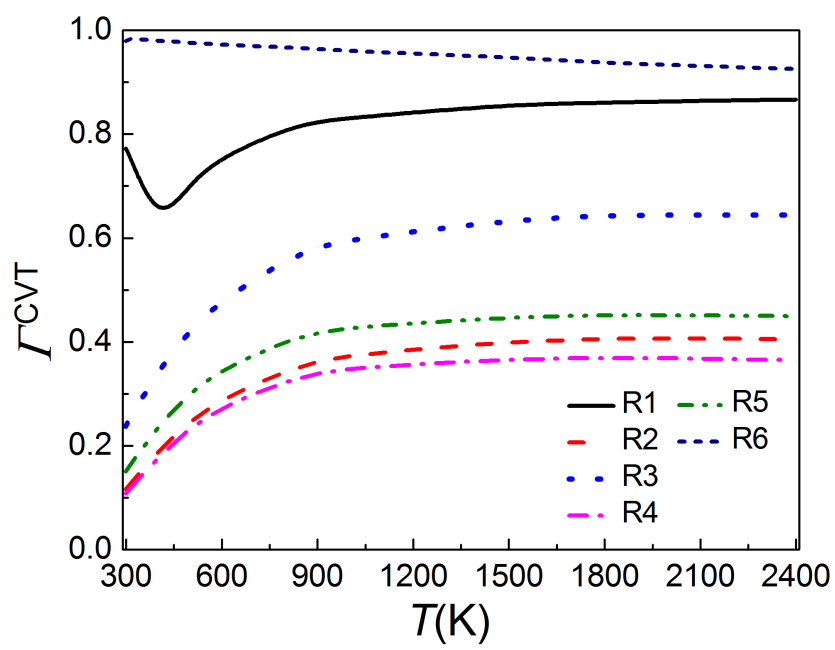

Figure 7. Canonical recrossing transmission coefficients $(\Gamma$ ${ }^{\mathrm{CVT}}$ ) for R1-R6 at various temperatures.

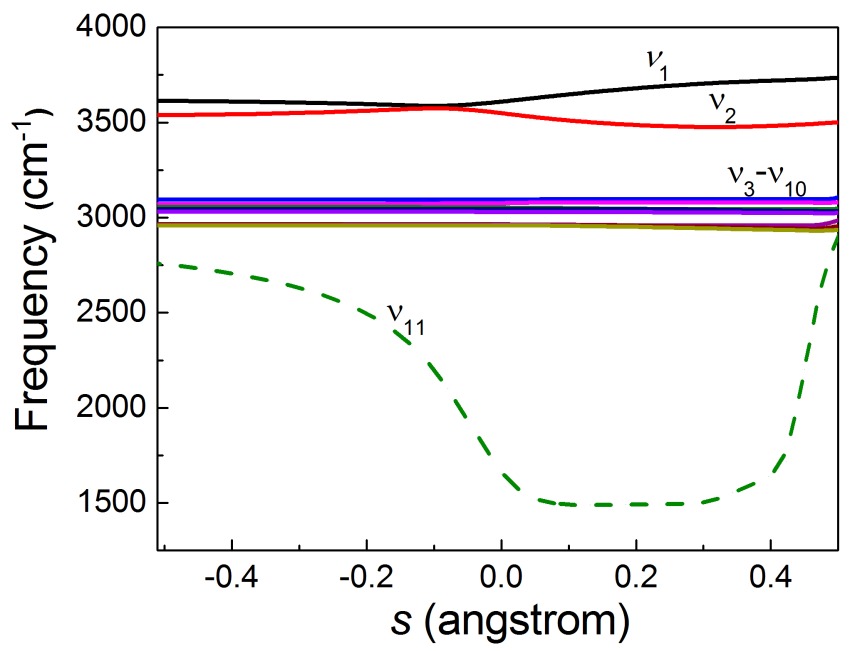

Figure 8. The eleven highest vibrational frequencies of R2 as functions of the reaction coordinate $s$. The saddle point is at $s=0$. 
3.4 Multidimensional tunneling effect. The multidimensional tunneling transmission coefficient includes the quantum mechanical tunneling effect and the contribution from nonclassical reflection at energies above the effective barrier. In the present work, using the vibrationally adiabatic ground-state potential energy as the effective potential curve and including corner-cutting tunneling by means of the effective mass, the small-curvature tunneling (SCT) approximation is used to calculate the multidimensional tunneling transmission coefficients. The multidimensional SCT tunneling transmission coefficients for the lowest-energy reaction paths (path 1 for each reaction) are plotted as functions of temperature in Figure 9 for R1-R6. These tunneling transmission coefficients show essentially no tunneling for $\mathrm{R}_{2}$ and $\mathrm{R}_{3}$ and range from 1.3 to 3.5 at $298 \mathrm{~K}$ for the other four reactions. The tunneling transmission coefficient for $\mathrm{R}_{5}$ is the largest among the lowest-energy paths for these six reactions, and it is 1.5 even at $600 \mathrm{~K}$.

Figure 10 shows the calculated tunneling transmission coefficients of R2 for paths 1, 2, 3, and 4. They are consistent with the previously discussed $V_{\mathrm{a}}^{\mathrm{G}}$ curves. As expected, the path with the highest energy barrier has the largest tunneling transmission coefficient. Comparing path 1 with path 4 ,we see a factor of 2.4 difference at room temperature.

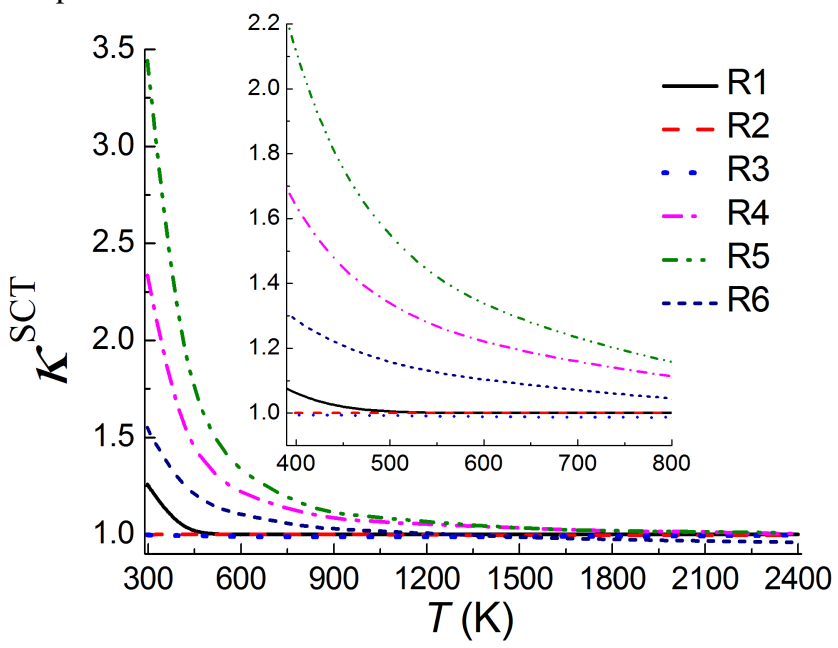

Figure 9. Small-curvature tunneling transmission coefficients $\kappa^{S C T}$ (for path 1 ) of reactions Ri-R6 at 298-2400 K.

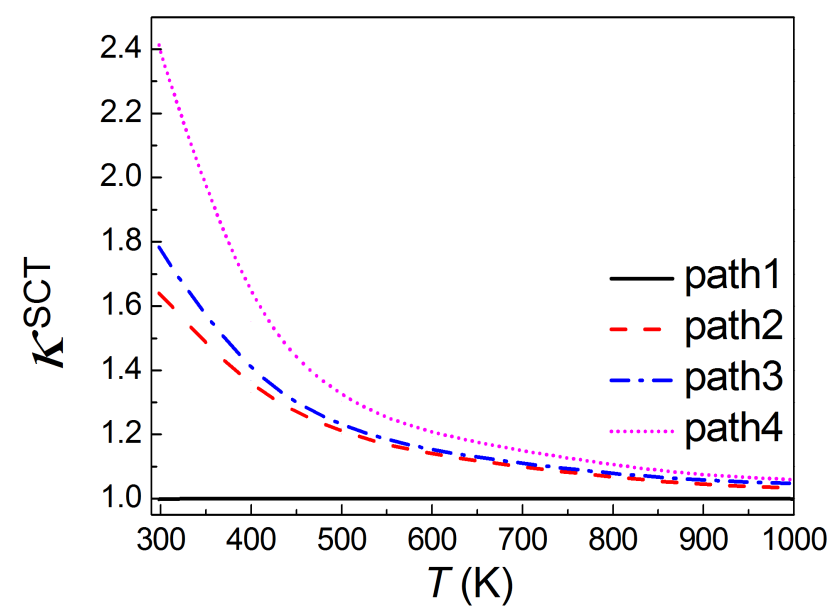

Figure 10. Small-curvature tunneling transmission coefficients $\kappa^{\mathrm{SCT}}$ of R2 for path 1 through path 4 at 298-1000 K.

3.5 MP-CVT/SCT rate constant. Path-averaged generalized transmission coefficients of reactions $\mathrm{R}_{1}-\mathrm{R}_{5}$ are in Table 5 for $P=1,2$, and 4 in eq 3 . These coefficients include the path-dependent variational effect and the pathdependent multidimensional tunneling effect. For example, for R2, the multidimensional tunneling coefficient from path 1 to path 4 increases (as shown in Figure 10), but the recrossing transmission coefficient is a nonmonotonic function of path label (as shown in Figure 6). Also, the single-structural rovibrational partition functions of the transition state computed with torsional anharmonicity are nonmonotonic functions of path number. These three factors all contribute to the final $\langle\gamma\rangle_{P}$. The resulting differences of $\langle\gamma\rangle_{2}$ from $\langle\gamma\rangle_{4}$ are $12 \%$ or less for $\mathbf{R}_{2}-\mathrm{R}_{5}$, but as large as $42 \%$ for R1. This shows that thermal rate constants can be significantly impacted by the higher-energy paths.

Since the forward reactions studied here are exoergic, we adopted the following fitting equations ${ }^{23,69}$ for the rate constants in the temperature range between 298 and 2400 $\mathrm{K}$ :

$$
k=A\left(\frac{T+T_{0}}{300}\right)^{n} \exp \left[-\frac{E\left(T+T_{0}\right.}{R\left(T^{2}+T_{0}^{2}\right)}\right]
$$

where $A, n, E, T_{o}$ are fitting parameters, and the ideal gas constant $R$ is $0.00198 \mathrm{kcal} \mathrm{mol}^{-1} \mathrm{~K}^{-1}$. The fitting parameters are tabulated in the SI.

The temperature-dependent Arrhenius activation energies $E_{a}$ can be derived from the local slopes of Arrhenius plots. For exothermic reaction, the resulting formula is:

$$
E_{a}=\frac{E\left(T^{4}+2 T_{0} T^{3}-T_{0}^{2} T^{2}\right)}{\left(T^{2}+T_{0}^{2}\right)^{2}}+\frac{n R T^{2}}{T+T_{0}}
$$

The temperature-dependent Arrhenius activation energies for R1-R6 are plotted in Figure 11. The activation energy increases dramatically with increasing temperature, especially in the temperature range of $298-600 \mathrm{~K}$. For instance, the deviation between $298 \mathrm{~K}$ and $600 \mathrm{~K}$ is 3.2, 12.8, $4.4,0.8,3.3 \mathrm{kcal} / \mathrm{mol}$ in the MP-CVT/SCT calculations for R1-R5 respectively. The MS-CVT/SCT activation energies are close to the MP-CVT/SCT ones except for R2, where the difference is due to the path dependence of quantum mechanical tunneling and multistructural anharmonicity.

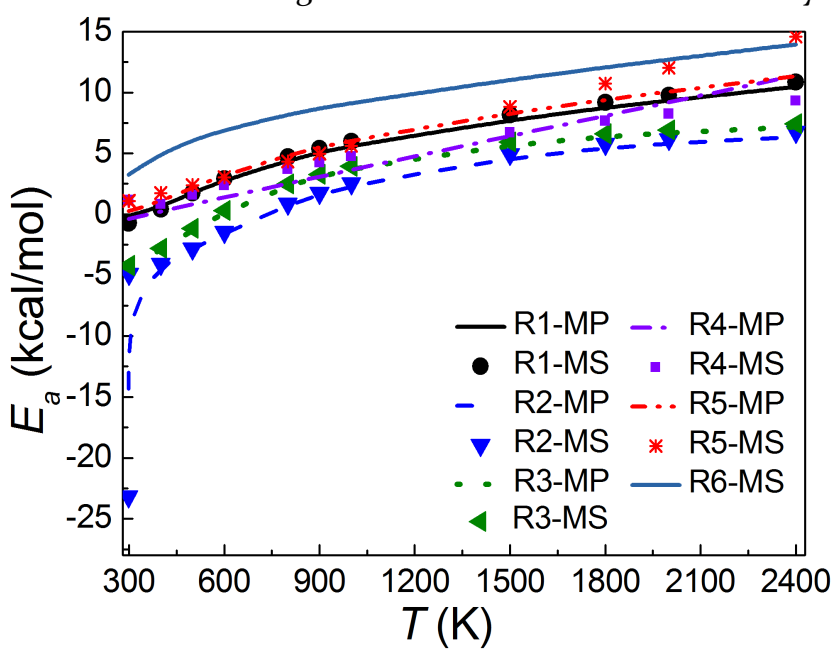


Figure 11. High-pressure-limit activation energies for R1-R6 at 298-2400 K. These symbols represent the MS-CVT/SCT results, and the lines are the MP-CVT/SCT results.

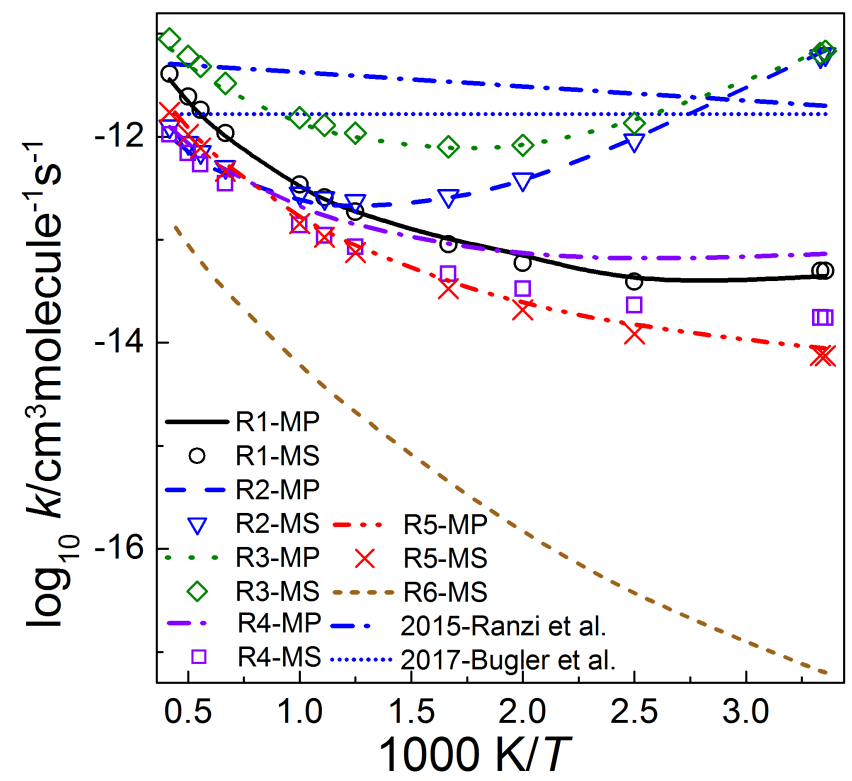

Figure 12. Calculated high-pressure-limit rate constants for R1-R6 at 298-2400 K using MP-CVT/SCT and MS-CVT/SCT. These symbols represent the MS-CVT/SCT results, and the lines are the MP-CVT/SCT results. We also compare to previous data for $\mathrm{R} 2$ which are from previous empirical model studies by Ranzi et al. ${ }^{16}$ and Bugler et al. ${ }^{19}$

Figure 12 shows the final high-pressure-limit MPCVT/SCT rate constants and the MS-CVT/SCT ones for R1-R6 in the temperature range of $\mathbf{2 9 8 - 2 4 0 0 ~ K}$. There are four noteworthy aspects: (i) For $\mathrm{R}_{1}, \mathrm{R}_{2}, \mathrm{R}_{3}$ and $\mathrm{R}_{5}$, the final MP-CVT/SCT rate constants and the MS-CVT/SCT ones are almost identical. (ii) The $\mathrm{H}$-abstraction reactions ( $\left.\mathrm{R}_{1}-\mathrm{R}_{5}\right)$ have larger rate constants than the addition reaction (R6). (iii) $\mathrm{R}_{2}$ and $\mathrm{R}_{3}$ have a stronger negative temperature dependence effect than the other reactions. (iv) At low temperatures $(298-400 \mathrm{~K})$, the rate constants of $\mathrm{R}_{2}$ and $R_{3}$ are close to each other, and $R_{3}$ begins to dominate as temperature is raised. We can explain aspect iv by a combination of three factors: (1) the entropy of $R_{3}$ is $\sim 2$ $\mathrm{cal} / \mathrm{mol} / \mathrm{K}$ larger than $\mathrm{R}_{2}$ (as can be seen in Table 3); (2) the influence of $T \Delta S$ is larger than the reaction enthalpy, especially at higher temperatures; (3) the recrossing transmission coefficients for $\mathrm{R}_{2}$ are $0.25,0.38,0.40$ and 0.41 at 500, 1000, 1500 and $2000 \mathrm{~K}$, respectively, but for $\mathrm{R}_{3}$ they are $0.42,0.60,0.64$ and 0.64 respectively, and these higher recrossing transmission coefficients for $\mathrm{R}_{3}$ contribute to the higher rate constants of $R_{3}$. However in most of current combustion modeling ${ }^{14-17,87}$, only $\mathrm{R}_{2}$ was taken into consideration and the corresponding kinetics data have been estimated empirically, such that they have no temperature dependence. As shown in blue dotted and dashed lines in Figure 12, in the temperature range of 500$1000 \mathrm{~K}$, the empirically estimated rates are a factor of $1.4^{-}$ 3.2 faster than our computed data.
The calculated branching fractions for R1-R6 as functions of temperature in the high-pressure limit are shown in Figure 13. The rate of reaction $\mathrm{R}_{7}$ is zero in the highpressure limit. Figure 13 also includes the branching fractions calculated using the single-structural harmonic conventional TST rate constants. The differences are large, and they reflect the cooperative contributions of the multistructural torsional effect, the variational effect, and the multidimensional tunneling effect.

3.6 Pressure-dependent rate constants. The SSQRRK theory ${ }^{25}$, which is used for predicting the falloff effect, allows one to conveniently incorporate variational effects, tunneling, and multistructural torsional anharmonicity into the calculations of energy-resolved rate constants needed for calculating pressure-dependent rate constants, without the complexity of solving the master equation or directly calculating the input to the master equation. The pressure-dependent rate constants $k_{\mathrm{R} 6}$ for the stabilization of P6 are plotted in Figure 14 in the temperature range of $298-2400 \mathrm{~K}$. In the temperature range of 298-60o K, the deviations of the rate constants at $100 \mathrm{~atm}$ from the HPL are factors of 1.2-4.3; thus the falloff effect cannot be neglected even in high-pressure engines. At atmospheric pressure $(1 \mathrm{~atm})$, the deviations of the rate constants from the HPL are factors of 21-324 for the lowtemperature range of $298-600 \mathrm{~K}$. As the temperature increases, the rate constants become even farther from the high-pressure limit.

The falloff curves are plotted in Figure 15 as $\log _{10}[k(p) / k(p=\infty)]$ versus pressure, where $k(p)$ represents the rate constant of the stabilization of P6 $\left(k_{\mathrm{R} 6}\right)$ at pressure $p$ and $k(p=\infty)$ represents the high-pressure-limit of the rate constant. The transition pressure $p_{1 / 2}$ is defined as the pressure where the rate constant is half of the highpressure-limit rate constant. ${ }^{88}$ We obtain $p_{1 / 2}(T)$ by interpolation from a table of $k(T, p)$ vs. $p$ at fixed $T$; the resulting $p_{1 / 2}(T)$ are plotted in Figure 16. At temperatures of 300, 400 , 500, and $600 \mathrm{~K}, p_{1 / 2}$ is 21, 69, 158, and 339 atm respectively. However, when the temperature increases above $1000 \mathrm{~K}, p_{1 / 2}$ increases rapidly with temperature. The pressure-dependent rate constants are fitted by the previously proposed formula ${ }^{89}$ (see the SI), with a fitting error of about $20 \%$ in the ranges $298 \mathrm{~K}$ to $1500 \mathrm{~K}$ and $0.1 \mathrm{~atm}$ to 10 atm; the fitting parameters are tabulated in the SI. 


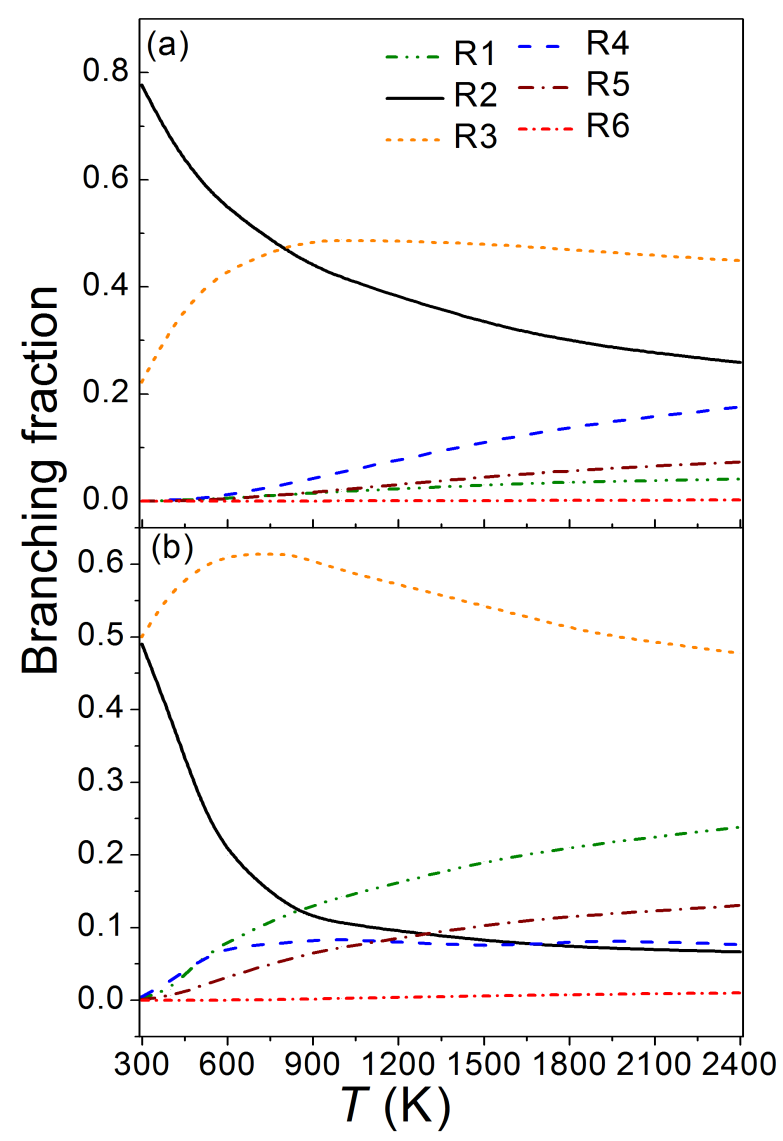

Figure 13. In the high-pressure limit, branching fractions of R1-R6 as functions of temperature computed by (a) singlestructural harmonic conventional TST and (b) MP-CVT/SCT. The branching fraction of reaction $\mathrm{R} i$ is computed as the ratio of rate constant of $\mathrm{Ri}$ to the overall rate constant (sum of the rate constants for all reactions).

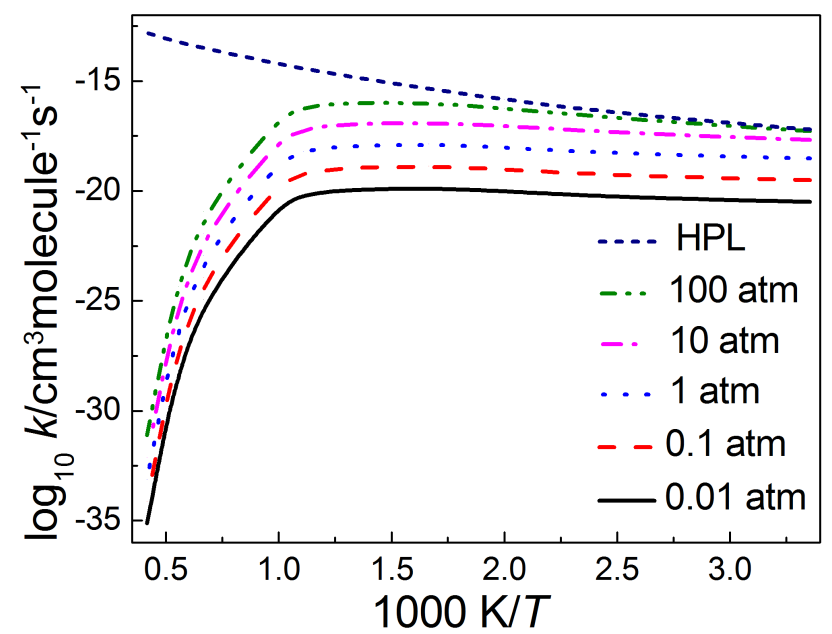

Figure 14. Computed rate constants for $k_{\mathrm{R} 6}$ (defined as the formation of the stabilized intermediate adduct P6) as functions of temperatures at 0.01, 0.1, 1.0, 10.0, 100.0 atm and in the high-pressure-limit (HPL) respectively.

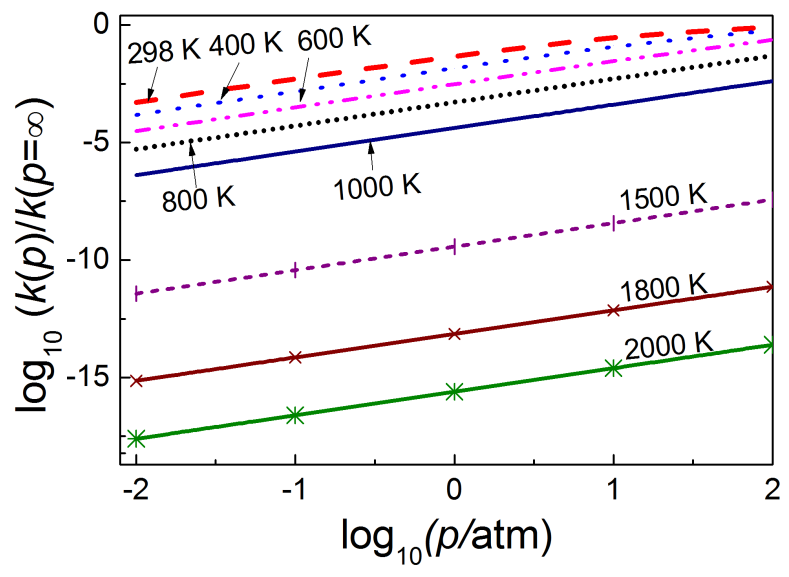

Figure 15. Predicted falloff curves for $k_{\mathrm{R} 6}$ (defined as the formation of the stabilized intermediate adduct-P6) as a function of pressure (atm) at various temperatures.

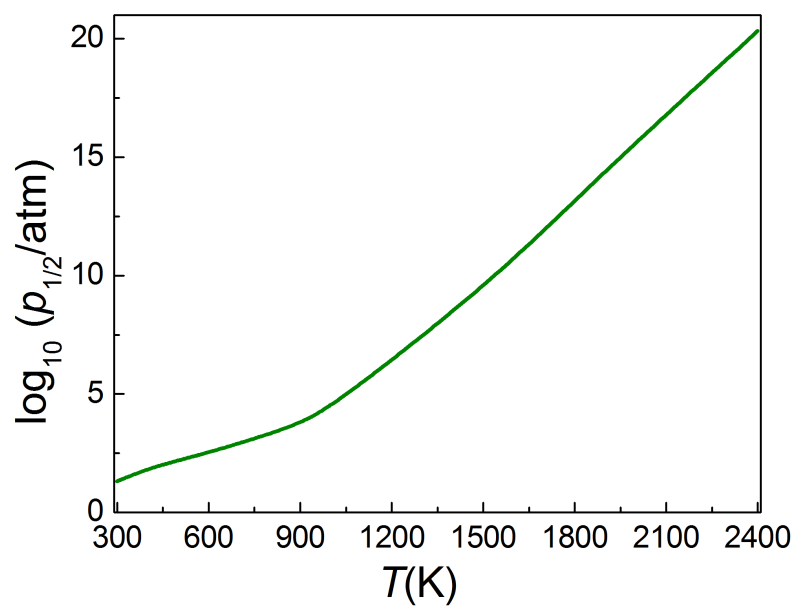

Figure 16. The transition pressure of the stabilization of P6 $\left(k_{\mathrm{R} 6}\right)$ as a function of temperature for Ar bath gas.

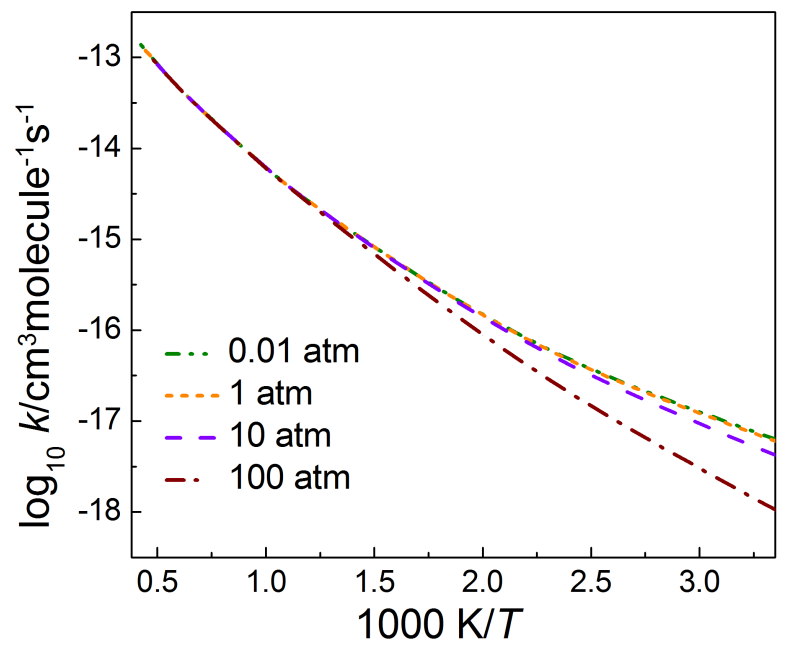

Figure 17. Rate constant of reaction $\mathrm{R}_{7}$ as a function of temperature at various pressures. 
As introduced in Section 2.2, $\mathrm{R}_{7}$ is a pressuredependent bimolecular reaction because there is a unimolecular intermediate (P6) in its reaction mechanism; the rate constants for the formation of the products $\mathrm{P}_{7}$ and $\mathrm{CH}_{3} \mathrm{COOH}\left(k_{\mathrm{R}_{7}}\right)$ are plotted as functions of temperature and pressure in Figure 17. The rate constant for $\mathrm{R}_{7}$ has no pressure dependence at $800-2400 \mathrm{~K}$, and over the whole temperature range studied, the rate constant for $\mathrm{R}_{7}$ is identical at $0.01 \mathrm{~atm}$ and $0.1 \mathrm{~atm}$. However at room temperature, the rate constant for the formation of $\mathrm{P}_{7}+$ $\mathrm{CH}_{3} \mathrm{COOH}$ at $1 \mathrm{~atm}$ is a factor of 5.8 larger than at $100 \mathrm{~atm}$. The falloff effect is greatly influenced by the energy transfer parameters. ${ }^{69}$ Thus we analyzed the sensitivity to $\Theta$ at various temperatures; for example the falloff curves for various $\Theta$ at $600 \mathrm{~K}$ are shown in Figure 18, and results at some other temperatures are provided in the SI. When $\Theta$ (and hence $\left\langle\Delta E>_{\text {down }}\right.$ ) is increased, the stabilization of P6 adduct rate constants becomes more efficient, the rate constant for R6 increases, and that for $\mathrm{R}_{7}$ decreases.

Figure 19 shows branching fractions of $\mathrm{H}$ abstraction, R6, and $\mathrm{R}_{7}$ as functions of temperature at ratm. The branching fractions at other pressures are provided in the SI. Here, H-abstraction denotes the total rate constants for all of $\mathrm{H}$-abstractions ( $\left.\mathrm{R}_{1}-\mathrm{R}_{5}\right)$. We can see the significant role of $\mathrm{H}$-abstractions $(\sim 99 \%)$ for the overall $\mathrm{KHP}+$ $\mathrm{OH}$ kinetics at finite pressures.

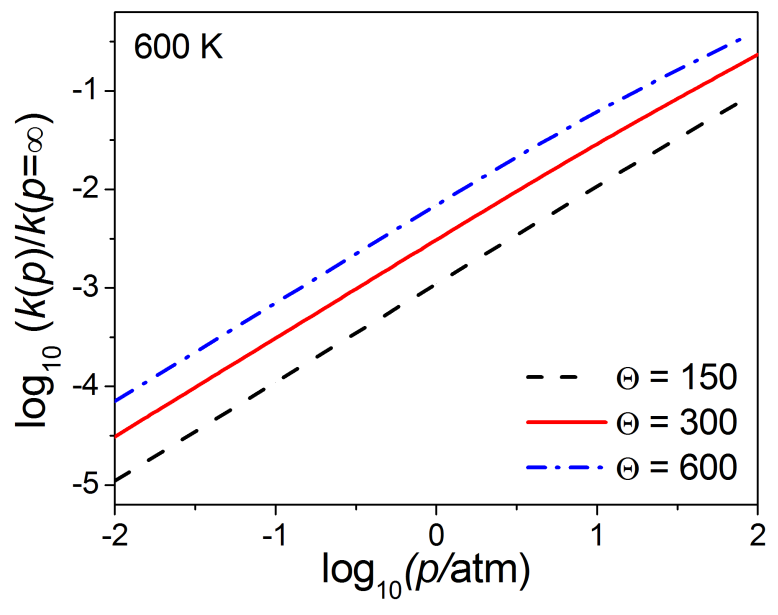

Figure 18. Predicted falloff curves for reaction R6 based on using different $\langle\Delta E\rangle_{\text {down }}$ parameters.

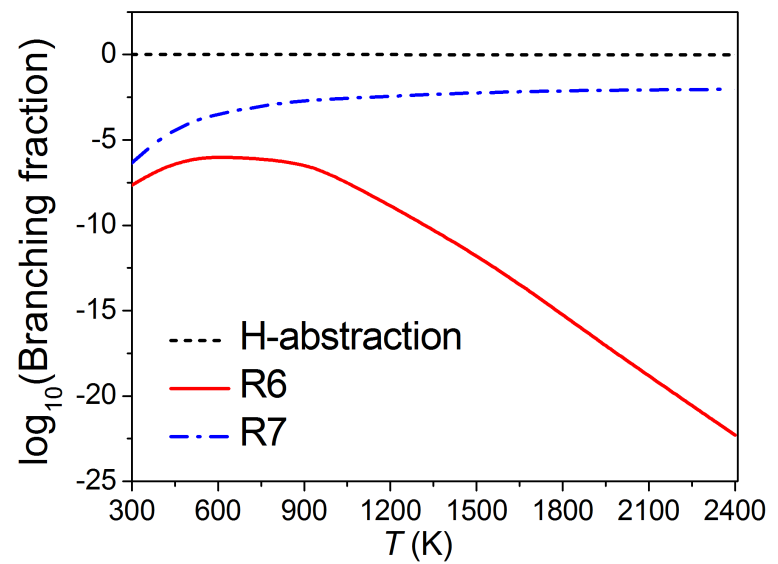

Figure 19. Branching fractions of $\mathrm{H}$-abstraction, $\mathrm{R} 6$, and $\mathrm{R}_{7}$ as functions of temperature at $1 \mathrm{~atm}$. The branching fraction of reaction $\mathrm{R} i$ is computed as the ratio of rate constant of $\mathrm{R} i$ to the overall rate constant $\left(\mathrm{R}_{1}-\mathrm{R}_{7}\right)$ and $\mathrm{H}$-abstraction denotes total rate constants for all of $\mathrm{H}$-abstractions ( $\left.\mathrm{R}_{1}-\mathrm{R}_{5}\right)$. 
Table 4. Computed standard-state entropy $(\mathrm{cal} / \mathrm{mol} / \mathrm{K})$, heat capacity $(\mathrm{cal} / \mathrm{mol} / \mathrm{K})$, and relative enthalpy $(\mathrm{kcal} / \mathrm{mol})^{\mathrm{a}}$ for KHP using different methods

\begin{tabular}{|c|c|c|c|c|c|c|c|c|c|c|c|}
\hline \multirow[b]{2}{*}{$T(\mathrm{~K})$} & \multicolumn{3}{|c|}{$S_{T}^{0}$} & \multirow[b]{2}{*}{$\mathrm{SS}^{-\mathrm{HO}^{\mathrm{C}}}$} & \multicolumn{4}{|c|}{$C_{P}^{0}(T)$} & \multicolumn{3}{|c|}{$H_{P}^{0}(T)$} \\
\hline & MS-LH & MS-T & $\mathrm{GA}^{\mathrm{b}}$ & & MS-LH & MS-T & $\mathrm{GA}^{\mathrm{b}}$ & SS-HO ${ }^{c}$ & MS-LH & MS-T & $\mathrm{SS}^{-\mathrm{HO}^{\mathrm{C}}}$ \\
\hline 298 & 104.3 & 104.6 & 106.6 & 95.7 & 40.7 & 41.2 & 37.7 & 36.0 & 99.9 & 100.1 & 98.5 \\
\hline 300 & 104.6 & 104.9 & 106.8 & 95.9 & 40.8 & 41.3 & 37.8 & 36.2 & 99.9 & 100.2 & 98.6 \\
\hline 400 & 117.4 & 117.7 & 118.5 & 107.6 & 48.5 & 48.1 & 45.4 & $45 \cdot 3$ & 104.4 & 104.6 & 102.7 \\
\hline 500 & 129.0 & 129.2 & 128.8 & 118.6 & 55.5 & 54.5 & 51.9 & 53.2 & 109.6 & 109.8 & 107.6 \\
\hline 600 & 139.7 & 139.6 & 138.0 & 128.9 & 61.5 & 60.1 & 57.5 & 59.8 & 115.5 & 115.5 & 113.3 \\
\hline 700 & 149.5 & 149.2 & 146.3 & 138.5 & 66.6 & 64.9 & 62.3 & 65.2 & 121.9 & 121.8 & 119.5 \\
\hline 800 & 158.7 & 158.2 & 153.5 & 147.6 & 70.9 & 68.9 & 66.4 & 69.8 & 128.8 & 128.4 & 126.3 \\
\hline 900 & 167.3 & 166.5 & 159.8 & 156.0 & 74.6 & 72.3 & 69.8 & 73.7 & 136.1 & 135.5 & 133.5 \\
\hline 1000 & $175 \cdot 3$ & 174.3 & 165.3 & 164.0 & 77.8 & 75.3 & 72.8 & 77.1 & 143.7 & 142.9 & 141.0 \\
\hline
\end{tabular}

a Zero of energy is set to potential energy of global minimum;

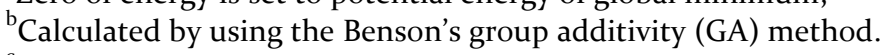

${ }^{\mathrm{C} C}$ Calculated using the lowest-energy equilibrium conformer.

Table 5. Averaged generalized transmission coefficient ${ }^{a}$ of reactions $\mathrm{R}_{1}-\mathrm{R}_{5}$

\begin{tabular}{lllllllllllllllll}
\hline & \multicolumn{3}{c}{$\mathrm{R} 1$} & \multicolumn{3}{c}{$\mathrm{R} 2$} & \multicolumn{3}{c}{$\mathrm{R}_{3}$} & & \multicolumn{3}{c}{$\mathrm{R}_{4}$} & \multicolumn{3}{c}{$\mathrm{R}_{5}$} \\
\cline { 2 - 15 } & $\langle\gamma\rangle_{1}$ & $\langle\gamma\rangle_{2}$ & $\langle\gamma\rangle_{4}$ & $\langle\gamma\rangle_{1}$ & $\langle\gamma\rangle_{2}$ & $\langle\gamma\rangle_{4}$ & $\langle\gamma\rangle_{1}$ & $\langle\gamma\rangle_{2}$ & $\langle\gamma\rangle_{4}$ & $\langle\gamma\rangle_{1}$ & $\langle\gamma\rangle_{2}$ & $\langle\gamma\rangle_{4}$ & $\langle\gamma\rangle_{1}$ & $\langle\gamma\rangle_{2}$ & $\langle\gamma\rangle_{4}$ \\
\hline 298 & 0.97 & 0.50 & 0.86 & 0.12 & 0.12 & 0.13 & 0.24 & 0.23 & 0.25 & 0.25 & 1.11 & 1.06 & 0.52 & 0.59 & 0.61 \\
400 & 0.64 & 0.29 & 0.59 & 0.19 & 0.18 & 0.19 & 0.34 & 0.32 & 0.34 & 0.28 & 0.80 & 0.76 & 0.46 & 0.56 & 0.54 \\
600 & 0.76 & 0.99 & 0.82 & 0.29 & 0.26 & 0.27 & 0.48 & 0.42 & 0.44 & 0.33 & 0.68 & 0.63 & 0.46 & 0.55 & 0.53 \\
800 & 0.81 & 0.94 & 0.79 & 0.34 & 0.29 & 0.30 & 0.56 & 0.47 & 0.49 & 0.36 & 0.64 & 0.59 & 0.46 & 0.57 & 0.53 \\
1000 & 0.83 & 0.93 & 0.78 & 0.38 & 0.31 & 0.32 & 0.60 & 0.50 & 0.52 & 0.37 & 0.61 & 0.56 & 0.47 & 0.59 & 0.54 \\
1500 & 0.86 & 0.92 & 0.77 & 0.40 & 0.32 & 0.33 & 0.64 & 0.51 & 0.53 & 0.38 & 0.56 & 0.51 & 0.46 & 0.60 & 0.53 \\
2400 & 0.87 & 0.93 & 0.76 & 0.41 & 0.31 & 0.33 & 0.64 & 0.51 & 0.53 & 0.37 & 0.50 & 0.44 & 0.45 & 0.61 & 0.52 \\
\hline
\end{tabular}

${ }^{a}$ The generalized transmission coefficient averaged over the first $P$ paths is defined as $\langle\gamma\rangle_{P}$ by eq 3 .

3.7 Implication for KHP chemistry. It is essentially impossible to detect the $\mathrm{H}$-abstraction reactions experimentally. First, the preparation and purification of KHP is a complex process. Second, storage is difficult because KHP is very active. Third, these $\mathrm{H}$-abstraction reactions can produce different products such as $\mathrm{P}_{1}, \mathrm{P}_{2}, \mathrm{P}_{3}, \mathrm{P}_{4}$, and $\mathrm{P}_{5}$, which are reactive radicals. Therefore theoretical calculations are essential for understanding these $\mathrm{H}$ abstraction reactions and their branching fractions.

The products of the reactions studied here can dissociate into diones, cyclic ethers, or olefenic ketones via the loss of $\mathrm{OH}$ and $\mathrm{HO}_{2}$ radicals. These products have been detected experimentally in $n$-pentane oxidation, ${ }^{14}$ and the present kinetics data may enable their more accurate inclusion in ignition modeling and atmospheric modeling. For example, the product of reaction $\mathrm{R}_{2}$ is an unstable hydroperoxy radical that will immediately decompose to pentadione plus an $\mathrm{OH}$ radical. This prompt liberation of an $\mathrm{OH}$ radical is important kinetically in both atmospheric and pre-ignition chemistry.

Recent experimental work by Wang et al. ${ }^{90}$ studied the auto-oxidation of $n$-heptane. In addition to the carbonyl hydroperoxide $\left(\mathrm{C}_{7} \mathrm{H}_{14} \mathrm{O}_{3}\right.$, abbreviated as $\left.\mathrm{C}_{7} \mathrm{KHP}\right)$, they detected mass peaks corresponding to $\mathrm{C}_{7} \mathrm{H}_{12} \mathrm{O}_{2}$ and $\mathrm{C}_{7} \mathrm{H}_{12} \mathrm{O}$ species. They proposed that these intermediates could be produced from the $\mathrm{H}$-atom abstraction of carbonyl hydroperoxide by $\mathrm{OH}$ radical. A possible structure of the $\mathrm{C}_{7} \mathrm{H}_{12} \mathrm{O}_{2}$ species is a $\mathrm{C}_{7}$ dione and/or a keto cyclic ether (e.g., with one carbonyl and one cyclic ether group); a possible structure of $\mathrm{C}_{7} \mathrm{H}_{12} \mathrm{O}$ is a heptenone. This experiment detection highlights the significant role in determining the formation of diones, alkenones, and keto cyclic ethers through $\mathrm{H}$-atom abstraction of carbonyl hydroperoxides. A consequence of the present work is that $\mathrm{C}_{5}$ diones and/or keto cyclic ethers (i.e., $\mathrm{C}_{5} \mathrm{H}_{8} \mathrm{O}_{2}$ ) and pentenones (i.e., $\mathrm{C}_{5} \mathrm{H}_{8} \mathrm{O}$ ) can result from the $\mathrm{H}$-atom abstraction of KHP, as shown in Figure S9 of the SI. To study this further, we selected one of the carbonyl hydroperoxides from $n$-pentane auto-oxidation to study $\mathrm{H}$-atom abstraction reactions by $\mathrm{OH}$ radical.

In the original $n$-pentane kinetic model by Bugler et al. ${ }^{17}$ the reaction pathways for $\mathrm{KHP}+\mathrm{OH}$ were not taken into consideration. To study the effect of these reactions, we updated the KHP mechanism in the original $n$ - 
pentane kinetic model of Bugler et al. ${ }^{17}$ by considering our new $\mathrm{KHP}+\mathrm{OH}$ rate constants, and we carried out a simulation with the updated mechanism. The subsequent reactions of the carbonyl hydroperoxide radicals, via $\beta-C-O$ scission, $\beta-\mathrm{O}-\mathrm{O}$ scission, cyclization, and concerted elimination, lead to $\mathrm{C}_{5} \mathrm{H}_{8} \mathrm{O}_{2}$ intermediates (e.g., in the notation of Fig. S9, these are $\mathrm{P}_{1-2}, \mathrm{P}_{2-1}, \mathrm{P}_{4-1}$, and $\left.\mathrm{P}_{5-1}\right)$ and $\mathrm{C}_{5} \mathrm{H}_{8} \mathrm{O}$ intermediates (e.g., $\mathrm{P}_{1-1}$ and $\mathrm{P}_{3}-1$ ). For the simulation, we required thermodynamic data for the new species in Figure S9 of the SI, and these data were estimated by THERM $^{91}$ to be consisted with the original model. The detailed model information for our simulation is provided in the SI.

The simulation was performed by using the CHEMKIN-PRO software ${ }^{92}$ using the perfect stirred reactor module. The input for the simulation is as follows: residence time $\mathrm{e}^{93}$ (which is defined as the ratio of the reactor volume and the volume flow rate of the gas flowing through the reactor) is set to be $2 \mathrm{~s}$, the pressure is $40 \mathrm{bar}$, the $n$-pentane mole fraction is $10000 \mathrm{ppm}$, the equivalence ratio (which is defined as the actual air fuel ratio divided by the air fuel ratio for complete combustion) is 0.4 , and the dilution gas is $\mathrm{N}_{2}$. We investigated the temperature range of $500-650 \mathrm{~K}$.

To learn the effect of the new rate constants on the products, we performed two simulations. In one, we updated the original $n$-pentane model ${ }^{17}$ by adding our new calculated rate constants of $\mathrm{R}_{1}-\mathrm{R}_{5}$. In the other, we only added $\mathrm{R}_{2}$ with an estimated rate constant of $1.67 \times 10^{-12}$ $\mathrm{cm}^{3}$ molecule $\mathrm{s}^{-1}$ (taken to have no temperature dependence), which is the value used in a previous reference. ${ }^{19}$ Results from these two simulations are compared in Figure 20. Figure 20(a) shows that the $\mathrm{H}$-abstraction reactions of KHP by $\mathrm{OH}$ radical and the subsequent reactions in Figure $\mathrm{S} 9$ of the SI produce several $\mathrm{C}_{5} \mathrm{H}_{8} \mathrm{O}_{2}$ and $\mathrm{C}_{5} \mathrm{H}_{8} \mathrm{O}$ intermediates. The highest-yield $\mathrm{C}_{5} \mathrm{H}_{8} \mathrm{O}$ isomer is a pentenone (i.e., $\mathrm{P}_{3-1}$ ) produced through pathways $\mathrm{R}_{3}$ and $\mathrm{R}_{4}$. The formation mole fractions of 2,4-pentanedione (i.e., $\mathrm{P}_{2-1}$ ) and a pentenone (i.e., $\mathrm{P}_{1-1}$ ) are comparable with the formation of $\mathrm{P}_{3}-1$. In contrast, the mole fractions of $\mathrm{C}_{5}$ keto cyclic ethers (i.e., $\mathrm{P}_{1-2}, \mathrm{P}_{4-1}$, and $\mathrm{P}_{5-1}$ ) are much lower. In Figure $20(\mathrm{~b})$, the mole fraction of 2,4-pentanedione $\left(\mathrm{P}_{2-1}\right)$ is five times higher than that in Figure 20(a). One of the main reasons is that the rate constant of $\mathrm{R}_{2} \mathrm{rec}-$ ommended by Bugler et al. ${ }^{19}$ is much higher than our calculation result in present work. The simulation we have just presented indicates that the new $\mathrm{H}$-abstraction reaction rates for reactions of $\mathrm{KHP}$ with $\mathrm{OH}$ lead to observable changes in the predicted production of downstream products in conditions related to auto-ignition. On the other hand, differences in reaction rate constants for the $\mathrm{H}$-atom abstraction reactions at different sites of KHP lead to a particular distribution of final products ( $\mathrm{P}_{1-1}, \mathrm{P}_{1}$ 2, P2-1...), which are not distinguished by current experimental diagnostics.

Although we performed high-level calculations for rate constants, directly using our results in a previously constructed combustion model will not necessarily lead to better agreement with experimental signals (such as final product distribution or ignition delay times), because of the uncertainty of the rate constants for other reactions that were previously added in the model, especially if the model contains some rate constants that were previously adjusted empirically to match the experimental data points. ${ }^{94}$ Nevertheless, the process of gradually adding more reliable data to the models should in the long run produce more reliable models of combustion.
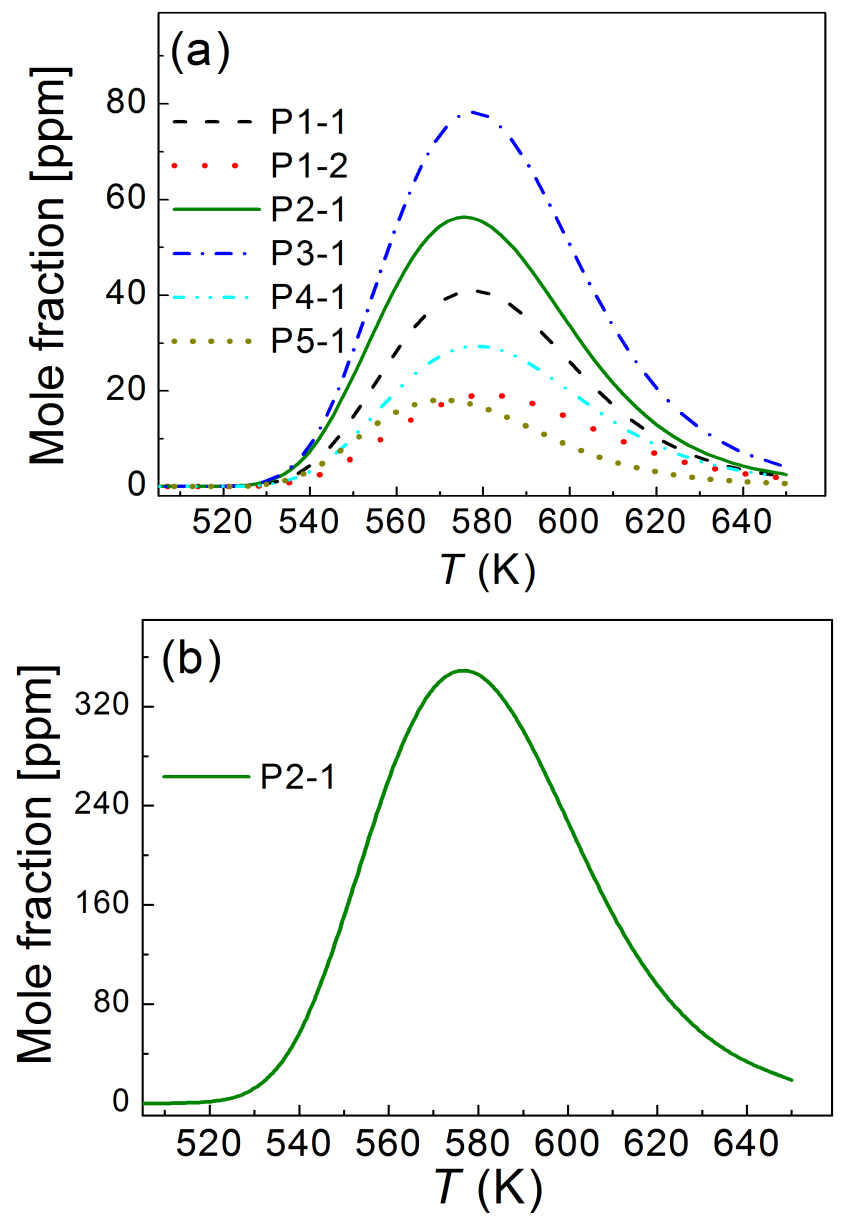

Figure 2o. Mole fraction profiles of $\mathrm{C}_{5} \mathrm{H}_{8} \mathrm{O}_{2}$ species (in particular $\mathrm{P}_{1-2}, \mathrm{P}_{2-1}, \mathrm{P}_{4-1}$ and $\mathrm{P}_{5-1}$ ) and $\mathrm{C}_{5} \mathrm{H}_{8} \mathrm{O}$ species (in particular $\mathrm{P}_{1-1}$ and $\mathrm{P}_{3-1}$ ) species during $n$-pentane autooxidation in a jet-stirred reactor at 40 bar. (a) Simulation with updated KHP mechanism by adding our new calculated rate constants of $\mathrm{R}_{1}-\mathrm{R}_{5}$ to the original $n$-pentane model $;^{17}$ (b) simulation by only adding Ref. 19's estimated rate constant of R2 (without adding other reactions) to the original KHP mechanism of Bugler et al. ${ }^{17}$

In the atmosphere, the products of the reactions studied here are expected to further associate with $\mathrm{O}_{2}$, which may contribute to the formation of secondary organic aerosols (SOA) via the formation of low-volatility organic compounds.

It would be interesting to investigate the reactions of other hydroperoxides with $\mathrm{OH}$ to learn how the rate constants vary. As a preliminary step in this direction, we calculated the classical energy barriers for reaction of $\mathrm{OH}$ with some simpler hydroperoxides. The formulas of the 
investigated molecules are $\mathrm{HOOCH}_{2} \mathrm{CH}_{2} \mathrm{CHO}$, which is called $\mathrm{C}_{3}, \mathrm{HOOCH}_{2} \mathrm{CH}_{2} \mathrm{C}(=\mathrm{O}) \mathrm{CH}_{3}$, which is called $\mathrm{C}_{4}-1$, and $\mathrm{CH}_{3} \mathrm{CH}(\mathrm{OOH}) \mathrm{CH}_{2} \mathrm{CHO}$, which is called $\mathrm{C}_{4}-2$. The detailed results are in Figs. $\mathrm{S}_{5}-\mathrm{S}_{7}$ of the SI, and they show the same trends as for the KHP investigated in the present work, which is 4-hydroperoxy-2-pentanone. In particular the $\mathrm{H}$-atom on the carbon bonded to the $\mathrm{OOH}$ group is the preferred reaction site, followed by the $\mathrm{OOH}$ group, and the least favorable abstraction site is the $\mathrm{H}$ atom on the $\mathrm{CH}_{3}$ group adjacent to the carbonyl group. The absolute values of energy barriers vary by about 1 $\mathrm{kcal} / \mathrm{mol}$ for the various hydroperoxides, e.g. for our KHP, as shown in Table 1, the energy barriers for TS2 and TS3 are -4.76 and $-2.73 \mathrm{kcal} / \mathrm{mol}$, and for $\mathrm{C}_{4}-2$, the corresponding energy barriers are -4.31 and $-2.25 \mathrm{kcal} / \mathrm{mol}$ respectively. Comparing KHP with $\mathrm{C}_{4}-\mathbf{1}$, the differences for $\mathrm{R}_{2}, \mathrm{R}_{3}$, and $\mathrm{R}_{4}$ are no larger than $0.18 \mathrm{kcal} / \mathrm{mol}$, but the barrier for abstraction of the $\mathrm{H}$-atom on the carbon bonded to $\mathrm{OOH}$ group is $0.61 \mathrm{kcal} / \mathrm{mol}$ higher for $\mathrm{C}_{4}-1$ due to the electronic effect of $\mathrm{CH}_{3}$ group. Our calculations on these small hydroperoxides with $\mathrm{OH}$ indicate that the general conclusions of the present work can be applied rather generally to the degradation of carbonyl hydroperoxides.

\section{CONCLUSIONS}

In this work, multipath and multistructural canonical variational transition-state-theory with small-curvature tunneling are used to calculate high-pressure-limit rate constants for hydrogen abstraction of ketohydroperoxide by hydroxyl radical., and the pressure-dependent rate constants have been computed for the addition reactions using the SS-QRRK method. Our calculations include accurate determinations of the classical barrier heights, the variational effects, internal-coordinate-based vibrationally adiabatic potentials, multistructural torsional anharmonicity, and multidimensional tunneling effects as put together by multipath VTST.

We found that multistructural anharmonicity has a large effect on the thermodynamic data, and it changes the rate constants by factors of 0.2 to 12 . The variational effect plays an important role in the determination of the rate constants, and it may be as large as a factor of 10 at low temperatures. We also found that the tunneling effect is large and cannot be ignored, e.g., the tunneling coefficient on reaction $\mathrm{R}_{4}$ (Boltzmann-averaged over four paths) is 4 at $298 \mathrm{~K}$ and 10 at $250 \mathrm{~K}$.

We find that $\mathrm{R}_{2}$ and $\mathrm{R}_{3}$ are the dominant reactions, and $\mathrm{R}_{3}$ is faster than $\mathrm{R}_{2}$ even though $\mathrm{R}_{2}$ has the lowest energy barrier. This result reflects the crucial role of variational effects and multistructural torsional anharmonicity, and the details of the present calculation show the importance of including these effects in combustion and atmospheric modeling.

The accurate thermodynamic and kinetics data computed in this work should be valuable for improving the accuracy of chemical kinetics models for alkane oxidation and the global modeling of secondary organic aerosols.

\section{ASSOCIATED CONTENT}

Supporting Information

Mean unsigned error of various tested electronic structure methods, barrier heights, reaction energies, thermodynamic data, partition functions, and fitting parameters, Cartesian coordinates and absolute energies, pathways analysis for the subsequent fate of products $\left(\mathrm{P}_{1}-\mathrm{P}_{5}\right)$, fitting formula and fitting parameters for the pressuredependent rate constants of $\mathrm{R} 6$ and $\mathrm{R}_{7}$, local periodicity values, the eleven highest and eleven lowest vibrational frequencies, predicted falloff curves for reaction R6 using different $\langle\Delta \mathrm{E}\rangle_{\text {down }}$ parameters, branching fractions as functions of temperature and pressure, $\mathrm{H}$-abstraction reaction mechanism of $\mathrm{KHP}+\mathrm{OH}$, comparison of energy barriers between our $\mathrm{KHP}+\mathrm{OH}$ reaction and some other small hydroperoxides $\left(\mathrm{C}_{3}\right.$ and $\left.\mathrm{C}_{4}\right)$ reacting with $\mathrm{OH}$. Input file for the CHEMKIN simulation.

The Supporting Information is available free of charge on the ACS Publications website at DOI: 10.1021/

\section{AUTHOR INFORMATION}

\section{Corresponding Authors}

* junweilucasbao@gmail.com

* feng2011@ustc.edu.cn

* truhlar@umn.edu

ORCID

Lili Xing: oooo-0oo3-2099-8472

Junwei Lucas Bao: oooo-0oo2-4967-663X

Zhandong Wang: oooo-0oo3-1535-2319

Feng Zhang: oooo-0oo2-9730-8487

Donald G. Truhlar: oooo-0oo2-7742-7294

\section{Notes}

The authors declare no competing financial interest.

\section{ACKNOWLEDGMENTS}

This work was supported in part by the U. S. Department of Energy, Office of Basic Energy Sciences, under Award Number DE-SCoo15997, by National Key Research and Development Program of China (No. 2016YFCo20260o), by National Natural Science Foundation of China (No. 91541112), and by the China Scholarship Fund. J. L. Bao acknowledges the financial support from doctor dissertation fellowship (DDF) provided by University of Minnesota.

\section{REFERENCES}

(1) Ehn, M.; Thornton, J. A.; Kleist, E.; Sipila, M.; Junninen, H.; Pullinen, I.; Springer, M.; Rubach, F.; Tillmann, R.; Lee, B.; Lopez-Hilfiker, F.; Andres, S.; Acir, I.-H.; Rissanen, M.; Jokinen, T.; Schobesberger, S.; Kangasluoma, J.; Kontkanen, J.; Nieminen, T.; Kurten, T.; Nielsen, L. B.; Jorgensen, S.; Kjaergaard, H. G.; Canagaratna, M.; Maso, M. D.; Berndt, T.; Petaja, T.; Wahner, A.; Kerminen, V.-M.; Kulmala, M.; Worsnop, D. R.; Wildt, J.; Mentel, T. F. Nature 2014, 506, 476-479.

(2) Crounse, J. D.; Nielsen, L. B.; Jørgensen, S.; Kjaergaard, H. G.; Wennberg, P. O. J. Phys. Chem. Lett. 2013, 4, 3513-3520. 
(3) Jokinen, T.; Sipilä, M.; Richters, S.; Kerminen, V.M.; Paasonen, P.; Stratmann, F.; Worsnop, D.; Kulmala, M.; Ehn, M.; Herrmann, H.; Berndt, T. Angew. Chem. Int. Ed. 2014, 53, 14596-14600.

(4) Mentel, T. F.; Springer, M.; Ehn, M.; Kleist, E.; Pullinen, I.; Kurtén, T.; Rissanen, M.; Wahner, A.; Wildt, J. Atmos. Chem. Phys. 2015, 15, 6745-6765.

(5) Berndt, T.; Richters, S.; Jokinen, T.; Hyttinen, N.; Kurtén, T.; Otkjær, R. V.; Kjaergaard, H. G.; Stratmann, F.; Herrmann, H.; Sipilä, M.; Kulmala, M.; Ehn, M. Nature Commun. 2016, 7, 13677.

(6) Blocquet, M.; Schoemaecker, C.; Amedro, D.; Herbinet, O.; Battin-Leclerc, F.; Fittschen, C. PNAS 2013, 110, 20014-20017.

(7) Westbrook, C. K. Proc. Combust. Inst. 2000, 28, 1563-1577.

(8) Xing, L.; Zhang, L.; Zhang, F.; Jiang, J. Combust. Flame 2017, 182, 216-224.

(9) Xing, L.; Zhang, F.; Zhang, L. Proc. Combust. Inst. 2017, 36, 179-186.

(10) Wang, Z.; Zhang, L.; Moshammer, K.; PopolanVaida, D. M.; Shankar, V. S. B.; Lucassen, A.; Hemken, C.; Taatjes, C. A.; Leone, S. R.; Kohse-Höinghaus, K.; Hansen, N.; Dagaut, P.; Sarathy, S. M. Combust. Flame 2016, 164, 386-396.

(11) Battin-Leclerc, F.; Herbinet, O.; Glaude, P.-A.; Fournet, R.; Zhou, Z.; Deng, L.; Guo, H.; Xie, M.; Qi, F. Angew. Chem. Int. Ed. 2010, 49, 3169-3172.

(12) Battin-Leclerc, F.; Herbinet, O.; Glaude, P.-A.; Fournet, R.; Zhou, Z.; Deng, L.; Guo, H.; Xie, M.; Qi, F. Proc. Combust. Inst. 2011, 33, 325-331.

(13) Xing, L.; Zhang, X.; Wang, Z.; Li, S.; Lidong, Z. Chin. J. Chem. Phys. 2015, 28, 563-572.

(14) Rodriguez, A.; Herbinet, O.; Wang, Z.; Qi, F.; Fittschen, C.; Westmoreland, P. R.; Battin-Leclerc, F. Proc. Combust. Inst. 2017, 36, 333-342.

(15) Rodriguez, A.; Herbinet, O.; Meng, X.; Fittschen, C.; Wang, Z.; Xing, L.; Zhang, L.; Battin-Leclerc, F. J. Phys. Chem. A 2017, 121, 1861-1876.

(16) Ranzi, E.; Cavallotti, C.; Cuoci, A.; Frassoldati, A.; Pelucchi, M.; Faravelli, T. Combust. Flame 2015, 162, 1679-1691.

(17) Bugler, J.; Marks, B.; Mathieu, O.; Archuleta, R.; Camou, A.; Grégoire, C.; Heufer, K. A.; Petersen, E. L.; Curran, H. J. Combust. Flame 2016, 163, 138-156.

(18) Zhang, K.; Banyon, C.; Bugler, J.; Curran, H. J.; Rodriguez, A.; Herbinet, O.; Battin-Leclerc, F.; B'Chir, C.; Heufer, K. A. Combust. Flame 2016, 172, 116-135.

(19) Bugler, J.; Rodriguez, A.; Herbinet, O.; BattinLeclerc, F.; Togbé, C.; Dayma, G.; Dagaut, P.; Curran, H. J. Proc. Combust. Inst. 2017, 36, 441-448.

(20) Sharma, S.; Raman, S.; Green, W. H. J. Phys. Chem. A 2010, 114, 5689-5701.

(21) Goldsmith, C. F.; Green, W. H.; Klippenstein, S. J. J. Phys. Chem. A 2012, 116, 3325-3346.

(22)Zheng, J.; Truhlar, D. G. Faraday Discuss. 2012 , 157, 59-88.

(23) Yu, T.; Zheng, J.; Truhlar, D. G. J. Phys. Chem. A 2012, 116, 297-308.
(24) Liu, Y. P.; Lynch, G. C.; Truong, T. N.; Lu, D. H.; Truhlar, D. G.; Garrett, B. C. J. Am. Chem. Soc. 1993, 115, 2408-2415.

(25) Bao, J. L.; Zheng, J.; Truhlar, D. G. J. Am. Chem. Soc. 2016, 138, 2690-2704.

(26) Bao, J. L.; Zhang, X.; Truhlar, D. G. Phys. Chem. Chem. Phys. 2016, 18, 16659-16670.

(27) Bao, J. L.; Truhlar, D. G. Phys. Chem. Chem. Phys. 2016, 18, 10097-10108.

(28) Zheng, J.; Mielke, S. L.; Clarkson, K. L.; Truhlar, D. G. Comput. Phys. Commun. 2012, 183, 1803-1812.

(29)Zheng, J.; Meana-Pañeda, R.; Truhlar, D. G. Comput. Phys. Commun. 2013, 184, 2032-2033.

(30) Zheng, J.; Mielke, S. L.; Bao, J. L.; Meana-Pañeda, R.; Clarkson, K. L.; Truhlar, D. G.; MSTor -version 2017; University of Minnesota: 1077 Minneapolis, M., 2017. https://t1.chem.umn.edu/mstor/update.htm 1078 (accessed May 5, 2017).

(31)Zhao, Y.; Truhlar, D. G. J. Chem. Theory Comput. 2008, 4, 1849-1868.

(32) Lynch, B. J.; Zhao, Y.; Truhlar, D. G. J. Phys. Chem. A 2003, 107, 1384-1388.

(33) Krishnan, R.; Binkley, J. S.; Seeger, R.; Pople, J. A. J. Chem. Phys. 1980, 72, 650-654.

(34) Frisch, M. J.; Pople, J. A.; Binkley, J. S. J. Chem. Phys. 1984, 80, 3265-3269.

(35) Stephens, P. J. D.; Devlin, F. J. C.; Chabalowski, C.

F. N.; Frisch, M. J. J. J. Phys. Chem. 1993, 98, 247-257.

(36) Lynch, B. J.; Fast, P. L.; Harris, M.; Truhlar, D. G. J. Phys. Chem. A 2000, 104, 4811-4815.

(37)Zhao, Y.; Schultz, N. E.; Truhlar, D. G. J. Chem. Theory Comput. 2006, 2, 364-382.

(38) Chai, J.-D.; Head-Gordon, M. Phys. Chem. Chem. Phys. 2008, 10, 6615-6620.

(39) Zhao, Y.; Truhlar, D. G. Acc. Chem. Res. 2008, 41, 157-167.

(40)Zhao, Y.; Truhlar, D. G. Theor. Chem. Acc. 2008, 120, 215-241.

(41) Peverati, R.; Truhlar, D. G. Phys. Chem. Chem. Phys. 2012, 14, 13171-13174.

(42) Peverati, R.; Truhlar, D. G. Phys. Chem. Chem. Phys. 2012, 14, 16187-16191.

(43) Yu, H. S.; He, X.; Li, S. L.; Truhlar, D. G. Chem. Sci. 2016, 7, 5032-5051.

(44) Yu, H. S.; He, X.; Truhlar, D. G. J. Chem. Theory Comput. 2016, 12, 1280-1293.

(45) Papajak, E.; Truhlar, D. G. J. Chem. Theory Comput. 2010, 6, 597-601.

(46) Adler, T. B.; Knizia, G.; Werner, H.-J. J. Chem. Phys. 2007, 127, 221106.

(47) Knizia, G.; Adler, T. B.; Werner, H.-J. J. Chem. Phys. 2009, 130, 054104.

(48) Papajak, E.; Truhlar, D. G. J. Chem. Phys. 2012, 137, 064110

(49) Papajak, E.; Truhlar, D. G. J. Chem. Theory Comput. 2011, 7, 10-18.

(50) Frisch, M. J. T., G. W.; Schlegel, H. B.; Scuseria, G. E.; Robb, M. A. C., J. R.; Scalmani, G.; Barone, V.; Mennucci,; B.; Petersson, G. A. N., H.; Caricato, M.; Li, X.; Hratchian, H.; P.; Izmaylov, A. F. B., J.; Zheng, G.; 
Sonnenberg, J. L.; Hada, M.; Ehara, M. T., K.; Fukuda, R.; Hasegawa, J.; Ishida, M.; Nakajima,; T.; Honda, Y. K., O.; Nakai, H.; Vreven, T.; Montgomery, J. A., Jr.;; Peralta, J. E. O., F.; Bearpark, M.; Heyd, J. J.; Brothers, E.; Kudin,; K. N.; Staroverov, V. N. K., R.; Normand, J.; Raghavachari, K.;; Rendell, A. B., J. C.; Iyengar, S. S.; Tomasi, J.; Cossi, M.; Rega,; N.; Millam, J. M. K., M.; Knox, J. E.; Cross, J. B.; Bakken, V.;; Adamo, C. J., J.; Gomperts, R.; Stratmann, R. E.; Yazyev, O.;; Austin, A. J. C., R.; Pomelli, C.; Ochterski, J. W.; Martin, R. L.;; Morokuma, K. Z., V. G.; Voth, G. A.; Salvador, P.;; Dannenberg, J. J. D., S.; Daniels, A. D.; Farkas, O.;; Foresman, J. B. O., J. V.; Cioslowski, J.; Fox, D. J. Gaussian 09, revision C.01; Gaussian, Inc.: Wallingford, CT, 2009.

(51)Zhao, Y.; Peverati, R.; Tang, K.; Luo, S.; Yu, H. S.; He, X.; Truhlar, D. G.; $M N-G F M$ 6.7; Department of Chemistry, U. o. M. M., MN, 2015.

(52) Werner, H.-J.; Knowles, P. J.; Knizia, G.; Manby, F. R.; Schütz, M.; Celani, P.; Korona, T.; Lindh, R.; Mitrushenkov, A.; Rauhut, G.; Shamasundar, K. R.; Adler, T. B.; Amos, R. D.; Bernhardsson, A.; Berning, A.; Cooper, D. L.; Deegan, M. J. O.; Dobbyn, A. J.; Eckert, F.; Goll, E.; Hampel, C.; Hesselmann, A.; Hetzer, G.; Hrenar, T.; Jansen, G.; Köppl, C. Y. L.; Lloyd, A. W.; Mata, R. A.; May, A. J.; McNicholas, S. J.; Meyer, W.; Mura, M. E.; Nicklass, A.; O’Neill, D. P.; Palmieri, P.; Peng, D.; Pflüger, K.; Pitzer, R.; Reiher, M.; Shiozaki, T.; Stoll, H.; Stone, A. J.; Tarroni, R.; Thorsteinsson, T.; Wang, M.; MOLPRO, v., a package of $\mathrm{ab}$ initio programs.

(53) Zheng, J.; Truhlar, D. G. J. Chem. Theory Comput. 2013, 9, 1356-1367.

(54) Yu, T.; Zheng, J.; Truhlar, D. G. Chem. Sci. 2011, 2, 2199-2213.

(55) Bao, J. L.; Sripa, P.; Truhlar, D. G. Phys. Chem. Chem. Phys. 2016, 18, 1032-1041.

(56) Bao, J. L.; Meana-Paneda, R.; Truhlar, D. G. Chem. Sci. 2015, 6, 5866-5881.

(57)Zheng, J.; Bao, J. L.; Meana-Pañeda, R.; Zhang, S.; Lynch, B. J.; Corchado, J. C.; Chuang, Y.-Y.; Fast, P. L.; Hu, W.-P.; Liu, Y.-P.; Lynch, G. C.; Nguyen, K. A.; Jackels, C. F.; Ramos, A. F.; Ellingson, B. A.; Melissas, V. S.; Villà, J.; Rossi, I.; Coitiño, E. L.; Pu, J.; Albu, T. V.; Polyrate2016-2A, U. o. M., Minneapolis, 2016, https:/comp.chem.umn.edu/polyrate/.

(58)Zheng, J.; Bao, J. L.; Zhang, S.; Corchado, J. C.; Meana-Pañeda, R.; Chuang, Y.-Y.; Coitiño, E. L.; Ellingson, B. A.; Truhlar, D. G.; Gaussrate 2017, U. o. M., Minneapolis, 2017, https://comp.chem.umn.edu/gaussrate/.

(59) Page, M.; McIver, J. W. J. Chem. Phys. 1988, 88, 922-935.

(60) Villa, J.; Truhlar, D. G. Theor. Chem. Acc. 1997, 97, 317-323.

(61) Alecu, I. M.; Zheng, J.; Zhao, Y.; Truhlar, D. G. J. Chem. Theory Comput. 2010, 6, 2872-2887.

(62) Nguyen, K. A.; Jackels, C. F.; Truhlar, D. G. J. Chem. Phys. 1996, 104, 6491-6496.

(63) Jackels, C. F.; Gu, Z.; Truhlar, D. G. J. Chem. Phys. 1995, 102, 3188-3201.
(64) Chuang, Y.-Y.; Truhlar, D. G. J. Phys. Chem. A 1998, 102, 242-247.

(65) Chuang, Y.-Y.; Truhlar, D. G. J. Chem. Phys. 1997, 107, 83-89.

(66) Fernandez-Ramos, A.; Ellingson, B. A.; Garrett, B. C.; Truhlar, D. G. 2007, 23, 125-232.

(67) Garrett, B. C.; Truhlar, D. G. J. Chem. Phys. 1979, 70, 1593-1598.

(68) Garcia-Viloca, M.; Gao, J.; Karplus, M.; Truhlar, D. G. Science 2004, 303, 186-195.

(69) Xing, L.; Li, S.; Wang, Z.; Yang, B.; Klippenstein, S. J.; Zhang, F. Combust. Flame 2015, 162, 3427-3436.

(70) Jasper, A. W.; Miller, J. A. J. Phys. Chem. A 2009 , $113,5612-5619$.

(71) Jasper, A. W.; Oana, C. M.; Miller, J. A. Proc. Combust. Inst. 2015, 35, 197-204.

(72) Klippenstein, S. J. Proc. Combust. Inst. 2017, 36, 77-111.

(73) Jalan, A.; Alecu, I. M.; Meana-Pañeda, R.; Aguilera-Iparraguirre, J.; Yang, K. R.; Merchant, S. S.; Truhlar, D. G.; Green, W. H. J. Am. Chem. Soc. 2013, 135, 11100-11114.

(74) Gilbert, R. G.; Smith, S. C. Theory of Unimolecular and Recombination Reactions, Blackwell, Oxford 1990.

(75) Bao, J. L.; Xing, L.; Truhlar, D. G. J. Chem. Theory Comput. 2017, 13, 2511-2522.

(76)Zheng, J.; Yu, T.; Papajak, E.; Alecu, I. M.; Mielke, S. L.; Truhlar, D. G. Phys. Chem. Chem. Phys. 2011, 13, 10885-10907.

(77) Chen, C.; Li, W. Z.; Song, Y. C.; Yang, J. J. Mol. Liq. 2009, 146, 23-28.

(78) Benson, S. W. Thermochemical Kinetics, WileyInterscience, New York, 2nd edn 1976.

(79) Ni, T.; Caldwell, R. A.; Melton, L. A. J. Am. Chem. Soc. 1989, 111, 457-464.

(80) Garrett, B. C.; Truhlar, D. G. J. Phys. Chem. 1979, $83,1079-1112$.

(81) Garrett, B. C.; Truhlar, D. G. J. Am. Chem. Soc. 1980, 102, 2559-2570.

(82) Garrett, B. C.; Truhlar, D. G.; Wagner, A. F.; Jr., T. H. D. J. Chem. Phys. 1983, 78, 4400-4413.

(83) Tucker, S. C.; Truhlar, D. G.; Garrett, B. C.; Isaacson, A. D. J. Chem. Phys. 1985, 82, 4102-4119.

(84) Garrett, B. C.; Truhlar, D. G. J. Phys. Chem. 1985, 89, 2204-2208.

(85) Garrett, B. C.; Abusalbi, N.; Kouri, D. J.; Truhlar, D. G. J. Chem. Phys. 1985, 83, 2252-2258.

(86) Garrett, B. C.; Truhlar, D. G. J. Am. Chem. Soc. 1979, 101, 4534-4548.

(87) Zhang, K.; Banyon, C.; Togbé, C.; Dagaut, P.; Bugler, J.; Curran, H. J. Combust. Flame 2015, 162, 41944207.

(88) Holbrook, K. A.; Pilling, M. J.; Robertson, S. H. Unimolecular Reactions, John Wiley \& Sons, New York, 2nd edn, 1996, chapter 2.

(89) Long, B.; Bao, J. L.; Truhlar, D. G. Phys. Chem. Chem. Phys. 2017, 19, 8091-8100.

(90) Wang, Z.; Chen, B.; Moshammer, K.; PopolanVaida, D. M.; Sioud, S.; Bhavani Shankar, V. S.; Vuilleumier, D.; Tao, T.; Ruwe, L.; Bräuer, E.; Hansen, N.; 
Dagaut, P.; Kohse-Höinghaus, K.; Raji, M. A.; Sarathy, S. Mani Combust. Flame 2017, accepted for publication.

(91) Ritter, E. R.; Bozzelli, J. W. Int. J. Chem. Kinet. 1991, 23, 767-778

(92) CHEMKIN-PRO 15112, R. D. S. D., (2012).

(93) Herbinet, O.; Dayma, G. In Cleaner Combustion:

Developing Detailed Chemical Kinetic Models; Battin-
Leclerc, F., Simmie, J. M., Blurock, E., Eds.; Springer London: London, 2013, p 183-210.

(94) Chen, D.; Wang, K.; Wang, H. Combust. Flame 2017, 186, 208-210. 
Table of Contents artwork

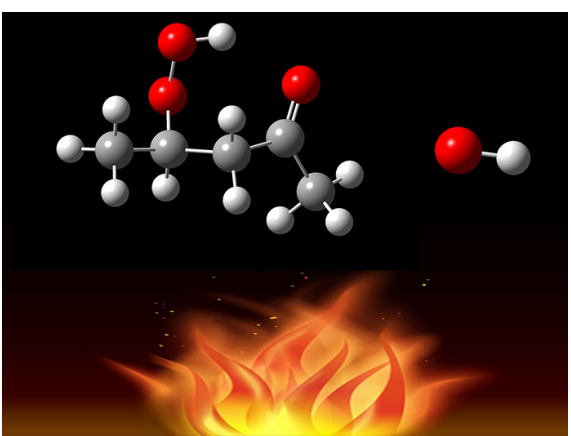

